\title{
Hydrothermal Vents: Oases at Depth
}

\subsection{Introduction to deep-sea ecosystems}

The deep ocean, often called the abyss, covers $66 \%$ of the planet. Schematically, it is the marine zone where there is not enough light to allow plants to grow. In fact, the lightened part of the ocean is shallow and does not exceed a few hundred meters; the rest of the ocean can reach much greater depths (11 km in the Mariana Trench) and is in complete darkness except for slight glows of bioluminescence. In the absence of local organic production, the organisms living at depth subsist due to organic matter produced in surface waters. This organic matter, in the form of decomposed matter, feces and molts, is clumped together by secretions from gelatinous organisms, sediments at depth and is degraded under the action of heterotrophic microbial communities, or is being recycled by pelagic organisms. Stratification of the water column, depth, surface production and seasonal variations as well as distance from continental shelves directly affect the flow of organic matter that reaches deep sediments.

Generally speaking, the further we move away from the coast, the greater the depth, the lower the organic input and consequently, the lower the benthic biomass. Production in the abyssis approximately a hundredth of the primary production at the surface and benthic biomass expressed in fresh weight rarely exceeds $2 \mathrm{~g} / \mathrm{m}^{2}$. Only some populations of filter-feeding

Chapter written by Jozée SARRAZIN and Daniel DESBRUYÈrES. 
organisms such as sponges and corals have significant biomass, concentrated in zones where deep currents resuspend sedimented organic matter. Moreover, surface plankton blooms occur which lead to the significant accumulation of organic matter at the water/sediment interface. This rapid enrichment of the environment allows for the rapid development of opportunistic fauna (small invertebrates and foraminifera) which disappears as the resource is depleted. Similarly, as the dead carcasses of large pelagic vertebrates (large fish, turtles and marine mammals) and plants (large algae and sunken wood) arrive at depth, they attract diverse populations of necrophages and xylophages (fish, mollusks and crustaceans) that rapidly use this food source and enrich the environment with their feces. The shortage of food, low temperatures (except for the Mediterranean Sea) and high hydrostatic pressure slow down biological processes such as growth and respiration.

Although the biomass, density and intensity of biological processes are low compared with coastal zones, the species diversity is high. A study of a sample of benthic macrofauna revealed that the population is composed of many species, each present in low numbers. Moreover, the similarity in faunal composition between samples taken in the same area is low, revealing the high biodiversity at a local scale. From these samples, the number of new species new to science is high, representing more than half of the sample. For example, in a total surface area of $21 \mathrm{~m}^{2}$, situated 2,100 $\mathrm{m}$ offshore of the New Jersey coast, an American team identified 798 species from a total of 90,677 individuals sampled, without the depletion curve reaching a plateau [GRA 92]. Extrapolating this curve would give a figure of 11,800 species of benthic macrofauna in this community.

Although many articles on the origin of deep-sea biodiversity, often contradictory, have been published, it is still difficult to draw a clear conclusion. Some of the oldest hypotheses suggest that the deep-sea environment is stable and in equilibrium and therefore not selective, leading to an unconstrained diversification and allowing the exploitation of different food sources. However, some researchers have recently suggested that the deep-sea environment is composed of a mosaic of small environments in disequilibrium caused by bioturbation and hydrodynamism (see Figure 6.1). Each of these environments would be colonized by successions of species responding to local conditions. 


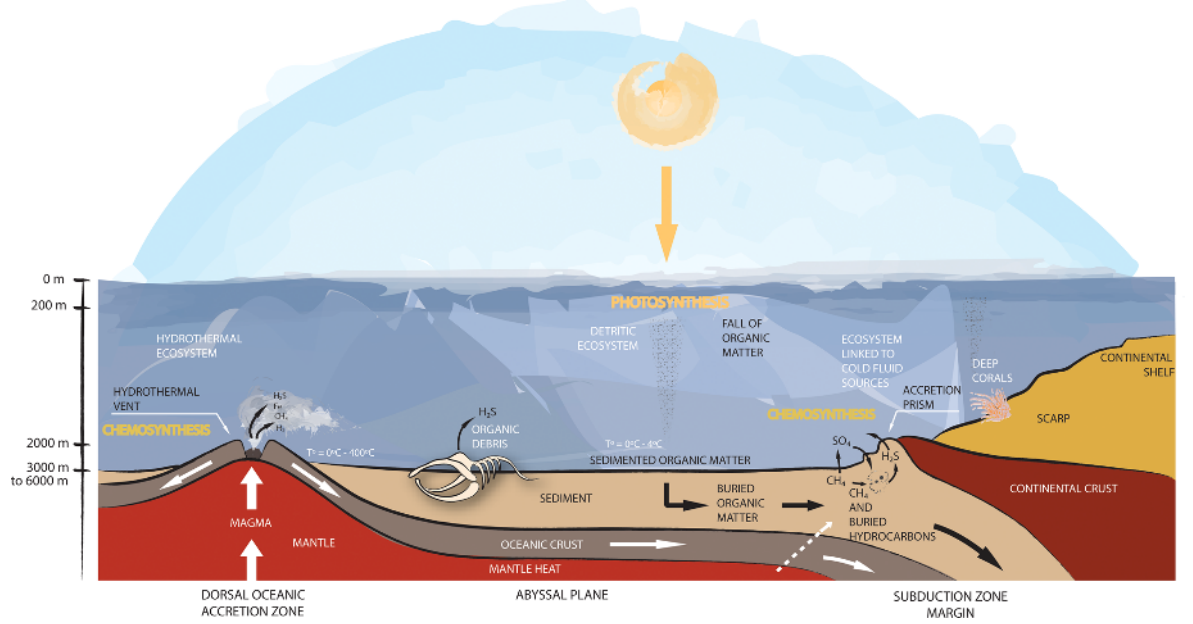

Figure 6.1. Cross-section of the ocean illustrating the different ecosystems of the deep sea (Capsule Graphik 2014)

Since the middle of the 19th Century, scientists have questioned the position of deep-sea animals in the evolution of marine fauna, in the hope that they might discover the missing link, i.e. the species or group that may have survived mass extinctions in this protected and stable environment. Currently, despite the discovery of primitive forms such as the mollusk Neopilina, many others reveal that the proportion of forms with ancient characteristics is much greater in the coastal and bathyal environment than in the abyss. Therefore, we have contrasting theories. The first theory considers that the abyssal fauna has evolved separately; the second theory proposes that this fauna is the result of successive migrations of coastal or bathyal species, particularly at high latitudes where temperature barriers are absent. In the history of the oceans, periods of anoxia at depth (e.g. between 90 and 50 million years ago), or the sharp change in temperature 16 million years ago, could have caused extinctions or significant variations in abyssal fauna, which would have been locally recolonized by fauna from continental margins.

At the beginning of the 1970s, our general vision of the deep-sea was that it was a relatively homogeneous ecosystem, with low benthic biomass, slow biological turnover, but high diversity of fauna. It was supplied by the fluxes of organic matter from photic zones of the ocean (see Figure 6.1). 


\subsection{Discovery of hydrothermal sources}

Measuring heat flows along the axis of ocean ridges reveals the existence of significant variations with lower values than what was predicted by heat transport models from convection in rocks. With this inconsistency between measurements, geophysicists were convinced that the lack of heat could be due to hydrothermal circulation in the crust, associated with the percolation of seawater. Indices of this circulation had also been revealed in 1974 on the Mid-Atlantic Ridge ${ }^{1}$, in the Franco-American program FAMOUS, in the form of metal deposits of hydrothermal origin. American geologists decided to explore not only a slow-spreading ridge as the MAR, but also a faster spreading ridge such as the one found in the Galapagos ${ }^{2}$. To locate potential sources of warm water, in May 1976, they used a "towcam" equipped with cameras and different sensors including temperature probes, towed several meters above the ridge situated at a depth of 2,500 $\mathrm{m}$. After several days, from the photos they noticed a coincidence between the presence of temperature anomalies and concentrations of white areas on black basalts. After analysis, these were considered to be large bivalve shells.

In February 1977, scientists arrived at the Galapagos onboard two oceanography vessels: "Lulu", a submersible support vessel for the submersible "Alvin" and the "Knorr". Alvin led the first dive of the campaign on 17 February 1977 at a depth of 2,500 $\mathrm{m}$ on the site found the previous year $\left(00^{\circ} 47^{\prime} \mathrm{N}\right.$ and $\left.86^{\circ} 09^{\prime} \mathrm{W}\right)$. Approximately $15 \mathrm{~min}$ after reaching the seafloor, the temperature probe on the submarine detected a temperature anomaly of several tenths of a degree and suddenly the landscape changed: through the portholes, astonished observers saw large white clams, aligned in faults between pillow lavas, anemones, mussel assemblages and orange mineral deposits [LON 77].

Here, in this mineral desert, a flourishing oasis of several hundred meters squared with diffuse emissions of warm water between 15 and $25^{\circ} \mathrm{C}$ was found; the temperature at these depths usually being around $2^{\circ} \mathrm{C}$. Quickly, several dives were planned and approximately $10 \mathrm{~km}$ away new sites were discovered, home to unique and colorful life forms. The first observations were fascinating and the sites were given poetic names such as "Rose Garden", "Clambake" or even "Garden of Eden". Large population of invertebrates was dominated by large

1 MAR: Mid-Atlantic Ridge.

2 GSC: Galapagos Spreading Center. 
bivalves such as the giant clam Calyptogena magnifica ${ }^{3}$ and the mussel Bathymodiolus thermophilus as well as the giant tubeworm Riftia pachyptila, which formed bushes of more than $1 \mathrm{~m}$ tall, composed of several hundred tubular individuals [HES 83].

Different chemical and isotopic measurements estimated that the pure hydrothermal fluid should reach much higher temperatures, probably between 300 and $400^{\circ} \mathrm{C}$; geophysicists were disappointed because the GSC fluids were very diluted. A new exploration program called RITA was, therefore, launched in 1978, in cooperation with French and Mexican teams, located on the East Pacific Rise ${ }^{4}$ between Rivera and Tamayo faults. In 1978, the French submarine Cyana discovered, at a depth of $2,645 \mathrm{~m}$, large sulfide structures of several meters tall and "cemeteries" of white bivalves with dissolved shells. The following year, the submersible Alvin brought American and French geophysicists to the same zone $\left(20^{\circ} 50^{\prime} \mathrm{N}\right.$ and $\left.109^{\circ} 06^{\prime} \mathrm{W}\right)$. After eight unsuccessful dives, the American team reported the presence of a chimney emitting black smoke. The first temperature measurements were unsuccessful, but then a temperature of $350^{\circ} \mathrm{C}$ was measured from this black fluid that was being emitted. The fauna at these sites was comparable to that at GSC sites, apart from the absence of mussels and the presence of a polychaete worm on the chimney walls, called the "Pompeii worm" (Alvinella pompejana) due to the hydrothermal ash covering its habitat.

The discovery of these areas of very high biomass surrounding hydrothermal fluid emissions located in the middle of a mineral desert and populated by unique organisms led the biologists to question the mechanisms of biological production in the absence of sunlight.

\subsection{Geology and geochemistry of hydrothermal systems}

\subsubsection{Formation of hydrothermal vents}

The distribution of hydrothermal emissions depends on geological and geochemical processes. These warm water emissions are formed in the different geodynamic contexts (slow and fast spreading ridges, back-arc basins and volcanic arcs), at depths varying from several meters to more than

\footnotetext{
3 For the taxonomic references see [DES 06a].

4 EPR: East Pacific Rise (with two subdivisions SEPR and NEPR, separated by the Amercian plate).
} 
$5,000 \mathrm{~m}$, at the boundary between two tectonic plates where new oceanic crust is formed. These plates move at speeds varying from several millimeters per year at slow ridges (such as the MAR) to 90 , or even $180 \mathrm{~mm}$ per year at fast ridges (as in the south of EPR). Unlike ridges that are the site of new oceanic crust formation, back-arc basins are formed in subduction zones. Located between the coasts and ocean trenches, these basins are also home to hydrothermal phenomena. The best known for their hydrothermal activity are the North Fiji Basin, the Okinawa area, the Lau Basin and the Manus Basin in the western Pacific and the East Scotia basin in the South Atlantic Ocean. Volcanic arcs can also contain active sites (e.g. South Sandwich arc in the Atlantic and Kermadec arc in the Pacific). A total of approximately 200 hydrothermal sites have been identified to date and several indices suggest the presence of several other active sites (see Figure 6.2), not including parts of the world that have never been explored, particularly at the poles.

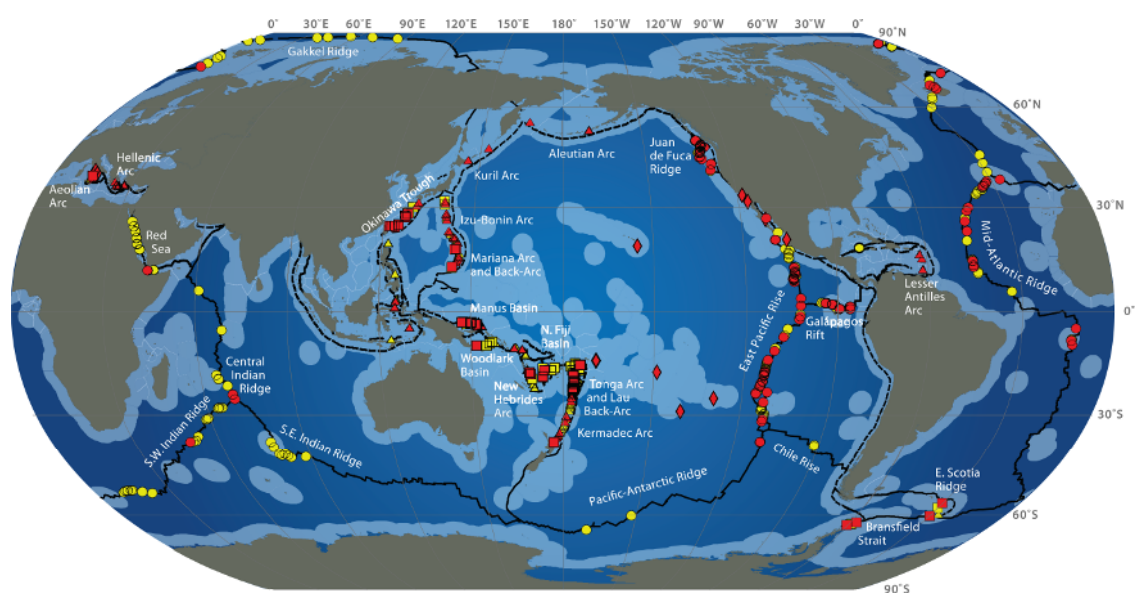

Figure 6.2. Distribution of active hydrothermal sites (in red) and sites where indices of activity have been identified (in yellow). Continuous lines represent ridges and faults whereas dotted lines represent trenches. Exclusive economic zones are indicated in pale blue (according to [BEA 10]). For a color version of the figure, see color section

Hydrothermal activity occurs due to the movement of tectonic plates and volcanic activity [FOU 12]. These intense geological processes favor a weakening of the seafloor and the creation of fissures in which cold and welloxygenated seawater (between 0 and $4^{\circ} \mathrm{C}$ ) will penetrate (see Figure 6.3). 
This seawater then reacts with the underlying rocks and undergoes modifications. The final composition of this "hydrothermal fluid" will depend on the composition of these rocks, the depth at which the seawater will percolate and subsurface temperatures. These zones of formation of the oceanic crust are characterized by the presence of shallower (only several kilometers) magma chambers than elsewhere in the ocean, which allows heating of the percolating fluids. These magma chambers contain magma with a melting point of $1,200^{\circ} \mathrm{C}$. Intense reactions cause the weathering of rocks and magnesium in the fluid to bind with new metals. This hot, acidic and rich in reduced compounds "hydrothermal fluid" is less dense and will rapidly rise to the surface of the seafloor to form a jet of hot water similar to a geyser called a "hydrothermal vent". The metals contained in the hydrothermal fluids precipitate in contact with the cold surrounding seawater to form polymetallic sulfides which accumulate and form structures reaching up several meters high. Hydrothermal plumes, formed by the dilution of hydrothermal fluid with seawater, rich in particles and characterized by temperature anomalies, can rise up to several hundred meters above active sites, until reaching neutral buoyancy. They then spread laterally according to the currents, favoring the dispersion of metals over tens of kilometers. They, therefore, significantly contribute to the input of chemical elements in the deep ocean.

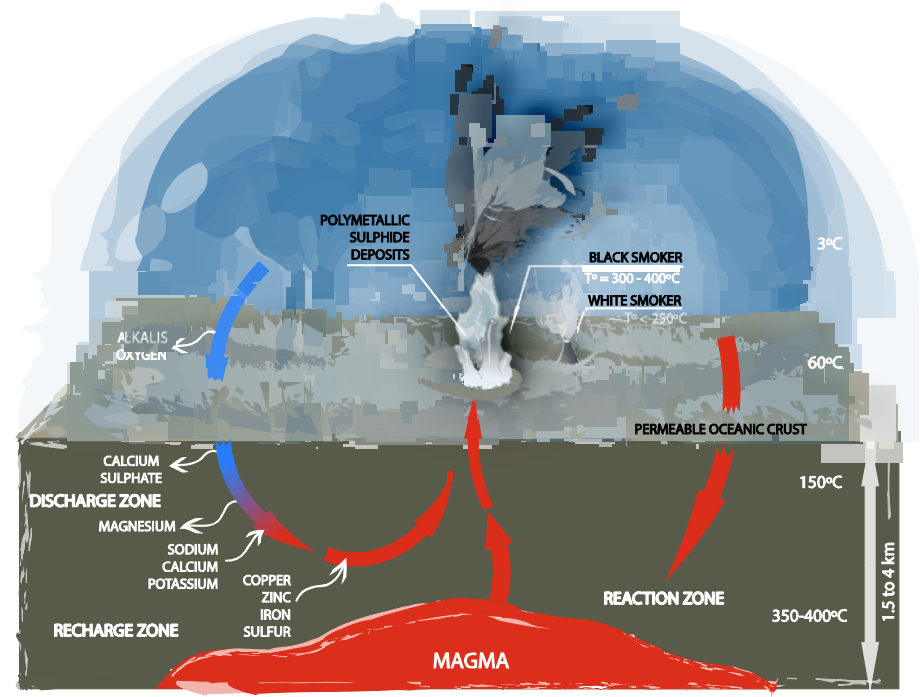

Figure 6.3. Diagram illustrating the circulation of fluids and the formation of hydrothermal vents (Capsule Graphik 2014) 


\subsubsection{Chemical composition of hydrothermal fluids}

All hydrothermal fluids are hot, acidic, free of oxygen and rich in sulfides and various metals such as iron, manganese, zinc, copper and also, in smaller proportions, cadmium, lead, cobalt, nickel, gold and silver. They are also rich in alkali metals (lithium, potassium, rubidium and cesium) and silica, which come from the leaching of basalts. Despite their similarities, these fluids have chemical compositions that vary from one area to another and even from one vent to another at the same site [CHA 00]. The final composition will depend on factors such as the geodynamic environment, water depth, temperature, the maturity of the deposits and the nature of the substrata affected by hydrothermal circulation. The reaction rate of seawater with this substratum is much faster at higher temperatures.

One particular chemical reaction, called serpentinization, occurs at several points along slow-spreading ridges. In this case, seawater reacts with the outcropping mantle rock, producing fluids extremely rich in hydrogen and methane. On the MAR, five active sites (Rainbow, Logatchev 1 and 2, and Ashadze 1 and 2) have been found on this mantle substrata. The final chemical composition of the fluids results from a pressure and temperature-dependent phenomena, which can lead to the process of phase separation. Thus, the critical point at which the seawater separates into two phases is at $400^{\circ} \mathrm{C}$, at a pressure of 300 bar (corresponding to $3,000 \mathrm{~m}$ depth). These two phases include a dense, saline solution rich in metals and a lighter fraction, rich in dissolved volatile gases. This phase separation process is responsible for large changes in salinity observed in hydrothermal fluids. There are also hydrothermal systems where the oceanic crust is buried under a thick layer of sediment due to the proximity to the coast and/or pelagic sedimentation. This is the case in the Guaymas Basin (Gulf of California), the Escanaba Trough (Gorda ridge) and the Middle Valley site (Juan de Fuca Ridge) located in the Pacific. There, the heat is trapped and fluids interact with sediment leading to the precipitation of sulfides and the formation of large deposits. The chemical composition of the fluids will then depend on that of the sediments and also on the importance of the reactions between these fluids, the surrounding basalts and buried sulfides. As these sediments trap metals, these sites are particularly rich in lead and arsenic [FOU 12].

The synthesis of organic molecules in hydrothermal fluids [HOL 01] raises the question of what role hydrothermal vents may have played in the emergence of life on Earth. Indeed, this environment contains the essential 
characteristics for the development of prebiotic syntheses: heat, water and the presence of basic chemical compounds. In addition, these deep-sea ecosystems were most likely protected from extreme conditions at the surface (meteor showers and ultraviolet radiation).

Several types of hydrothermal emissions exist, according to the degree of mixing between the vent fluids and cold seawater. Black smokers are the most spectacular. They result from a pure hydrothermal fluid, which does not undergo any dilution prior to being emitted. They can reach temperatures above $350^{\circ} \mathrm{C}$. These emissions are characterized by dense plumes of black smoke created by the precipitation of metal sulfides in contact with cold seawater. The vent diameter, which can reach $10 \mathrm{~cm}$, promotes the release of high-speed fluids at several meters per second. As the sulfide structure ages, the flow is reduced, the ducts become clogged and the fluid continues to percolate through porous minerals, sometimes forming very special black beehive structures. When the hydrothermal emissions last for thousands of years in one place, they can generate the formation of impressive sulfide mounds. Gray or white smokers emit fluids with temperatures ranging between 150 and $270^{\circ} \mathrm{C}$, which are more diluted and less rich in chemical elements. Their color is related to silica, anhydrite and barite that precipitate during mixing of hydrothermal fluids and seawater. Finally, the dilution of the hydrothermal fluids with seawater is even greater in the case of diffuse emissions, with temperatures below $50^{\circ} \mathrm{C}$. The fluid formed creates a shimmering effect linked to the difference in density with the cold surrounding seawater. It is in this diluted hydrothermal fluid, at moderate temperatures, that the hydrothermal fauna is found.

The chemical composition of hydrothermal fluids also varies over time: while it can remain stable for many years at some sites, it can also change slowly or even suddenly during volcanic or major tectonic events. Thus, the composition of the fluids on fast-spreading ridges appears to change faster than on slow-spreading ridges, where it would tend to remain more or less stable. The lifespan of a site can vary from tens to tens of thousands of years.

\subsection{Microbial chemosynthesis}

In the first months after the discovery of hydrothermal vents, the possible primary production of organic matter by autotrophic microbes was suggested 
[LON 77]. Producing organic matter requires an energy source, a carbon source and a source of electrons. In the case of photosynthesis, the energy source is light, $\mathrm{CO}_{2}$ is the source of carbon and water is the source of electrons (see Figure 6.4). Although water and $\mathrm{CO}_{2}$ are abundant in deep environments, the light required for photosynthesis is absent. Microbial chemosynthesis (or chemolithoautotrophy) is, therefore, an organic synthesis pathway, first discovered in 1887 by Sergei Winogradsky, a Russian microbiologist. This researcher, who studied soil biology, found out that filamentous bacteria were able to synthesize their cellular carbon from inorganic compounds, sulfides and carbon dioxide. This pathway analogous to photosynthesis differs in the origin of energy used to operate the $\mathrm{CO}_{2}$ condensation cycles [JAN 79].

In the case of aerobic chemosynthesis, oxygen is the most common electron acceptor and the electron donor is usually a form of reduced sulfur (sulfide, elemental sulfur and thiosulfate), but also iron, manganese and ammonium. At hydrothermal vents, the most abundant compound in the fluids is hydrogen sulfide or dihydrogen sulfide $\left(\mathrm{H}_{2} \mathrm{~S}\right)$ but methane, iron and hydrogen can also be used [SCM 08]. Chemosynthesis cannot, as it has often been claimed, be separated from solar energy, since it uses oxygen, a product of photosynthesis. When oxygen is absent, the main electron donor is hydrogen which is often present in large quantities in hydrothermal fluids; nitrates, sulfates, sulfur and $\mathrm{CO}_{2}$ acting as electron acceptors. In chemosynthesis, carbon fixation usually occurs in the Calvin-Benson cycle. However, in certain bacteria or archaea, other pathways may be used. Methanotrophy may also be a primary biosynthetic pathway if methane is synthesized abiotically. It can be used as a carbon source and an electron donor.

Although the role of chemosynthetic production in the hydrothermal ecosystem is generally acknowledged, some authors [KAR 95] state that its importance has not been clearly proven, and other possibilities should be considered, such as the recycling of organic matter within hydrothermal circulation and the formation of hydrocarbons or fatty acids, or the abiotic thermogenesis of organic compounds which could be used by heterotrophic microorganisms. The hydrothermal environment is inhabited by microorganisms (bacteria and archaea), with highly diverse metabolisms that populate almost all microenvironments including the turbulent mixing zone between warm fluids and cold seawater, water column, and biological and mineral surfaces. Filamentous bacteria can, particularly on soft sediments, develop in thick mats. 


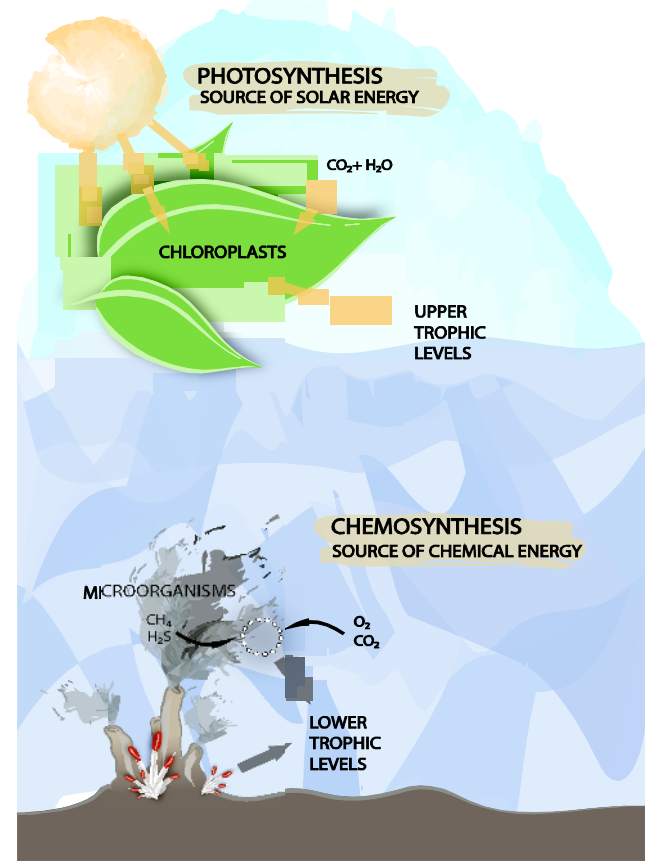

Figure 6.4. Photosynthesis and chemosynthesis: two processes producing an organic matter that uses different energy sources (Capsule Graphik 2014)

The discovery of hydrothermal oases was quickly followed by the discovery of cold seep zones (reviewed by Sibuet and Olu-Le [SIB 02]) on continental margins. Microbial production in this case is primarily based on the use of methane of biological origin as a carbon source and an electron donor. Besides direct methanotrophy, consortia of bacteria and archaea present in the sediments can transform methane into sulfides [BOE 00], which are used in chains of chemoautotrophic microbes. Similar populations to those observed in hydrothermal ecosystems have been found. Significant organic inputs (large vertebrate carcasses and sunken wood), which provide food for necrophages and xylophages, are also the site of anaerobic microbial degradation producing sulfides from sulfates in seawater. These sulfides will form the basis of chemosynthesis. Similar populations of organisms to those found in hydrothermal or deep ecosystems also develop around these large inputs of organic matter. 


\subsection{Symbioses and trophic chains}

The vent food web appears to be relatively simple: a local microbial production using energy from reduced minerals and a set of filter feeders and grazers, which form the second level become prey for carnivores, crabs and fish. Studying the intriguing giant tubeworm Riftia pachyptila and other engineer species provides key information to the functioning of this ecosystem.

\subsubsection{Symbioses}

\subsubsection{Riftia pachyptila}

These giant tubeworms have impressive dimensions (see Figure 6.5). Their tubes can exceed $1.5 \mathrm{~m}$ long and measure up to $6 \mathrm{~cm}$ in diameter. They are found as upright populations, comprising several tens to several hundred individuals. The chitinous tube is usually pearly white and a red plume emerges from its apical end. Their zoological phylogeny has long been debated. First classified in Obturata, a subphylum of the pogonophores, which include worms with a vestimentum (dorsal chamber of the body) and in the phylum vestimentifera, distinct from pogonophores, they are now classified with other members of pogonophores in a family of annelid polychaetes, Siboglinidae, similar to Sabellidae. Studying their anatomy reveals some interesting features. The highly vasculated, lamellar gill plume ends in a type of operculum, the obturaculum, which closes the tube when the animal retracts. The muscular vestimentum, situated between the tentacular crown and trunk, has two wing-like folds forming a chamber in which a pair of genital openings is located. The elongated sack-like trunk terminates in an opistosome with bristles anchoring in the tube. However, the most unexpected feature in an animal of this size is the absence of a gut. This absence, found in all adults of this species, obviously raises the question of their feeding mode. Dissection reveals that most of the trunks are occupied by a highly vascularized solid tissue, which was initially hypothesized, in a closely related species (Lamellibrachia Barhami), to having role in the formation of sperm. Closer analysis of this trophosome via transmission electron microscopy soon revealed that its cells were inhabited by symbiotic bacteria located inside vacuoles and were interspersed with elemental sulfur crystals. These bacterial populations may represent up to a quarter of the volume of this nutritive tissue. 


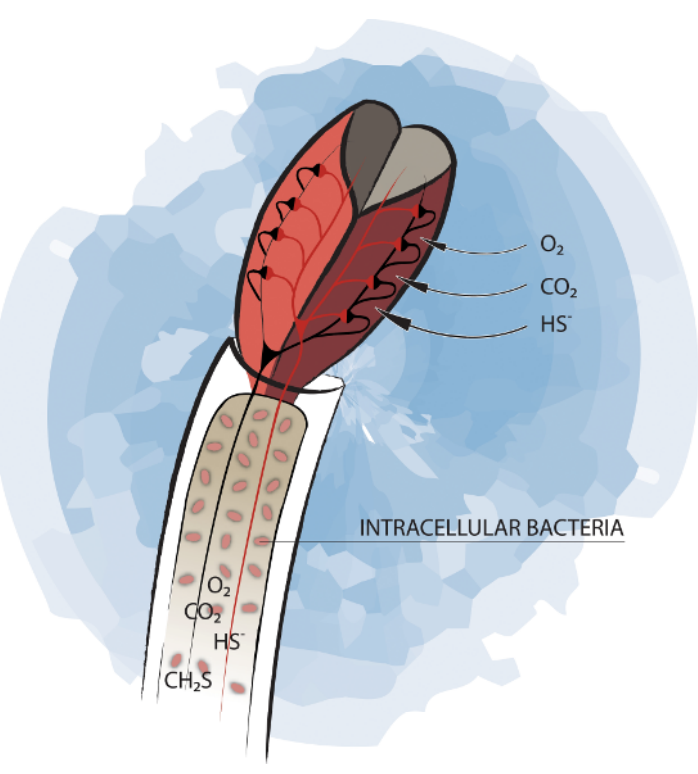

Figure 6.5. Endosymbiosis in the siboglinid worm Riftia pachyptila (Capsule Graphik 2014)

Biochemists have revealed that this trophosome harbors high activity of RubisCo, a diagnostic enzyme in the Calvin-Benson cycle, a biochemical cycle used in autotrophy and a characteristic enzyme in sulfur compound cycles. In addition, studying natural isotope ratios of carbon demonstrated that the worm tissues were not made of carbon from photosynthesis [FIS 90]. Recent studies on proteomes have also shown that these symbionts were able to use a different metabolic pathway of carbon fixation (rTCA) which requires less energy than the Calvin-Benson cycle. Together, these observations show that the tubeworm exploits the organic matter produced by its symbiotic bacteria found inside its bacteriocytes. The worm transfers the nutrients needed for the chemosynthesis bacteria via the bloodstream and in exchange, the bacteria provide it with the organic compounds necessary for its growth, metabolism and reproduction. To acquire the oxygen and sulfides required by bacteria, the worm's plume must be in a turbulent mixing zone where rich hydrothermal fluids alternate with oxygenated seawater [CHI 92].

This type of strict symbiosis is very productive. Sequential observations made after an eruption showed a tube growth of about $80 \mathrm{~cm}$ per year for a 
new Riftia colony, which is probably a record for a marine invertebrate. Research into embryonic development has shown that Riftia eggs give birth to trochophore larvae. In the next stage, the gut is formed from the oralarea. The bacteria are still lacking, while the gut is already functional. Free bacteria present in the external environment invade the worms and the trophosome is then formed from the walls of the midgut. Recent genomic analyses of Riftia's symbionts ( $\gamma$-proteobacteria) show that they have the genes required for autotrophy, as well as heterotrophy, which were probably used during the free larval phase in open water, out of active sites.

\subsubsection{Calyptogena magnifica}

Giant tubeworms are not the only ones to have a very productive symbiosis with chemosynthetic bacteria. The large clam Calyptogena magnifica belongs to the family Vesicomyidae, whose members are mostly burrowing bivalves. Often exceeding $25 \mathrm{~cm}$ at its greatest length, it has thick gills, very red and highly vasculated flesh, and a large muscular foot, which can be inserted deep into the cracks through which warm hydrothermal fluid is released [ARP 84]. The gut is reduced and it is likely that it is little or not functional. The hypertrophied gill immersed in seawater drawn in through the siphon located opposite to the foot [CHI 91]. Studies on carbon stable isotopes show that this animal does not use, or only slightly uses, carbon from photosynthesis. Enzymatic analyses reveal the strong autotrophic activity of Rubisco in gill tissues. Finally, histological studies confirmed the presence of symbiotic bacteria in the vacuoles of the bacteriocytes located on the outer edge of the gill filaments and sulfur crystals in the intercellular spaces. Sulfides are absorbed through the foot, whereas oxygen is stored and transported by haemoglobins in the blood. Various measurements of shells indicate a growth rate varying between 0.5 and $6 \mathrm{~cm} /$ year, with a maximum size reached after 20 years. These growth rates are not exceptional but are generally higher than those measured in coastal species. Unlike in Riftia tubeworms, the transmission of symbionts occurs during reproduction inside the maternal oocyte.

\subsubsection{Bathymodiolus thermophilus}

Bathymodiolus thermophilus mussels are found in the Eastern Pacific and belong to Mytilidae. These true mussels aggregate on the basalts and also on each other using their byssus. They reach a maximum size of approximately $20 \mathrm{~cm}$. They are located in low diffusion zone areas and they can even be observed in places where no hydrothermal activity is present, 
highlighting the high ecological plasticity of this species. Mussels contribute to the horizontal dispersion of fluid, which diffuses through cracks over several meters, allowing a lateral extension of their habitat [JOH 94]. They have a functional gastrointestinal tract, virtually similar to that of their coastal counterparts. The labial palps are used to concentrate the particles collected by their syphons, and their ciliated esophagus allows transport toward the stomach. The animal has the ability to very efficiently filter microorganisms from seawater. However, even if the gut is functional, the gill is thicker and four or five times larger than in other Mytilidae. Histological studies of the gill lamellae reveal that their lateral sides are mainly occupied by bacteriocytes which have large vacuoles full of chemosynthetic bacteria [CHI 92]. Elemental sulfur and lysosomes, which are membrane sacs containing the enzymes necessary to digest bacteria, are observed in these bacteriocytes. The mussels do not have protein molecules in their blood that transport oxygen or sulfides and therefore depend on the diffusion of gases from the environment into their palleal liquid. The toxicity of sulfides is controlled by their rapid oxidation into thiosulphates, which will be used in chemosynthesis. Due to the flexibility of their diets, from symbiosis to filtration, mussels are formidable competitors of other hydrothermal species.

\subsubsection{Alvinella pompejana}

Pompeii worms, colonizing the active chimneys of the EPR, differ completely in their morphologies from everything that was previously seen in polychaete annelids. Although they share some characters similar with Ampharetidae, it was soon clear that a new family, Alvinellidae, needed to be created among the Terebellomorpha [DES 98]. Unlike other families in this group, there is no clear separation between the thorax and abdomen, and a complex anchoring system is present on anterior segments. Two different species, Alvinella pompejana and A. caudata, were observed during the first dives at vents, both being extracted from organic tubes forming an intricate network on the walls of active chimneys. Their maximum sizes are approximately $150 \mathrm{~mm}$. They appear to withstand high temperatures for metazoan organisms. Their circulatory system and pigments are well adapted to life in hypoxic environments with the presence of a very large gill surface area and circulating haemoglobin with a very high oxygen affinity and a coelomic liquid rich in red blood cells in order to withstand the internal extreme conditions of the tube. These worms have lamellar gills, a functional gastrointestinal tract and retractile tentacles in the oral cavity as in 
Ampharetidae. However, the most surprising character of these animals is the presence of abundant white filaments, which are located in the intersegmental areas and form a very abundant dorsal felting. These are actually abundant colonies of filamentous bacteria embedded in the epidermal secretions of the worm. The inner tube is covered with large diverse microbial populations. Bacterial epibioses are common in marine invertebrates, but they are rarely present on all harvested individuals and are not systematically associated with specialized morphological structures. However, if the epibiont population in the worm is dominated by four strains of filamentous bacteria, it is clear that it must be much more diverse and function in a more complex way. Genetic analyses revealed the existence of a filamentous enzyme, ATP citrate-lyase, characteristic of the rTCA cycle for $\mathrm{CO}_{2}$ fixation. Two non-exclusive hypotheses have been proposed to explain this epibiosis. The first hypothesis states that there is a complex feeding relationship, by enrichment of the internal environment of the tube into organic matter, the worm mainly feeds from bacteria in the tube. This assumption has not been clearly confirmed by labeling experiments on the seabed. The second hypothesis involves bacteria in the detoxification process inside the tube. Such an association is observed, for example in rice where commensal bacteria on the roots transform sulfides into less toxic sulfites. We must await the results of ongoing experiments to validate these hypotheses. Pompeii worms colonize one of the most hostile environments on our planet, which is also a microbial habitat where primary production is significant.

\subsubsection{Rimicaris exoculata}

The deep-sea shrimp Rimicaris exoculata colonizes all known active sites in the MAR. They can form dense swarms of thousands of individuals close to the emission zones. The digestive contents of $A$. exoculata are composed of mineral particles from chimney surface and the isotope ratios of muscle tissue indicate that they feed on organic chemosynthetic material. Inside their dilated branchial chamber, some oral appendages are enlarged with long lamellae that beat in the thoracic cavity to ventilate the gills. This appendix has long setae on which filamentous bacteria grow, they are similar to those in Alvinella pompejana. Further research into microbial populations reveals that other microbial strains are present in the communities of the gill chamber. Experience in in situ simulated conditions [PON 13] shows that commensal bacteria in the gill chamber exhibit a chemoautotrophic metabolism and that nutritional transfers between these bacteria and the shrimp probably occur throughout the teguments. Research into genes involved in the carbon cycle 
[HÜE 11] reveals the existence of a complex community of microorganisms that interact in this symbiosis. Two groups of dominant filamentous bacteria belong to sulfur-oxidizing bacteria: the $\varepsilon$-proteobacteria using the rTCA pathway and $\gamma$-proteobacteria using the Calvin-Benson pathway for autotrophic synthesis. $\delta$-proteobacteria, also present, may reduce sulfur compounds (sulfates, elemental sulfur and thiosulfate) into sulfides, thus making it available for the other two groups of bacteria.

\subsubsection{Trophic network}

Apart from the presence of these large symbiotic species, forming the majority of the biomass, the trophic network of hydrothermal ecosystems is similar to those observed in other marine ecosystems. In addition to primary autotrophic producers (here, microorganisms), there are several primary and secondary heterotrophic consumers which include suspension feeders, grazers, deposivores, predators and necrophages. Besides endosymbioses and epibioses, several primary production compartments are present either in suspension in the water, fixed on different surfaces, living in the vent plume and that derived from surface processes [VAN 00] (see Figure 6.6).

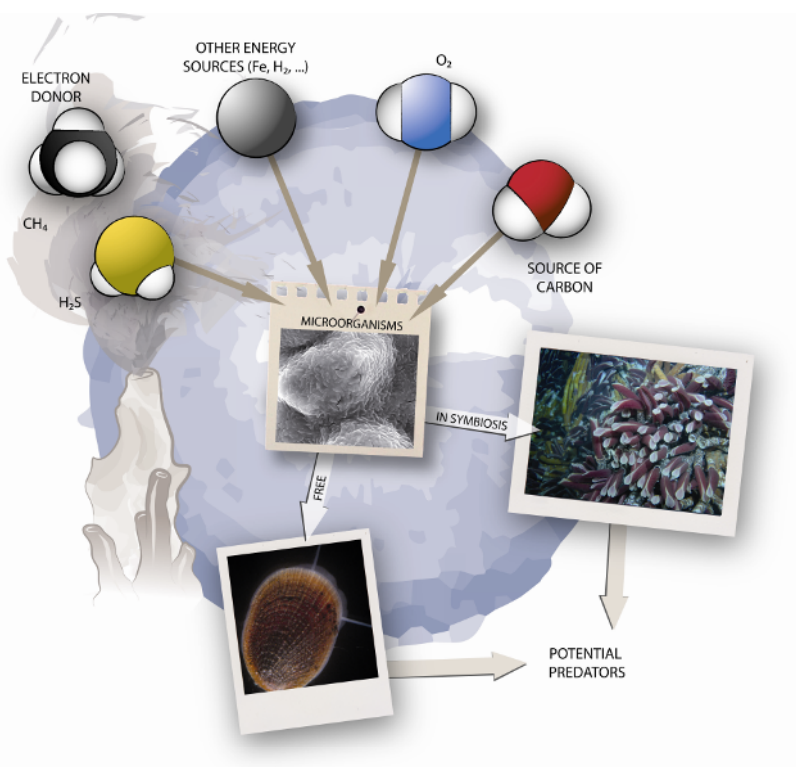

Figure 6.6. Simplification of the hydrothermal trophic network (Capsule Graphik 2014) 
Given the large animal biomass, the microbial production at hydrothermal vents is undoubtedly very large. Some sites, such as the Southern Trough Hydrothermal Field in the Guaymas Basin, are covered with dense microbial mats that alone form a microhabitat. These mats are also present, but to a lesser extent, on hydrothermal organisms. Microbial production in suspension can support large populations of filter feeding organisms such as barnacles, serpulids and anemones. This is the case on the SEPR ridge where barnacle fields can cover large areas or in Trans-Atlantic Geotraverse (TAG) and Ashadze sites on the MAR, which are surrounded by dense anemone fields.

The first model of hydrothermal food chain was proposed by Hessler and Smithey [HES 83] for the Rose Garden site on the GSC. There, primary producers include symbionts and free-living microorganisms. The primary consumers consist of engineer taxa living in symbioses: mytilids, vesicomyids and siboglinids. These hosts would be consumed, depending on the taxa, by carnivorous gastropods, crabs, shrimp and squat lobsters. However, the freeliving microorganisms would be consumed by grazing limpets, polychaetes and small crustaceans (amphipods and leptostraca) or filtered by serpulids, anemones, siphonophores, enteropneusta and small crustaceans. A parasitic or commensal polynoid worm lives in the mantle of mussels and other parasites, particularly copepods, were identified. Finally, deep-sea predators, such as octopus and fish, take advantage of the abundant organic matter near active sites. This first model has benefited from new methods of analysis that have helped consolidate certain assumptions and also review some interactions in the food web.

The isotopic analyses of carbon $\left(\delta^{13} \mathrm{C}\right)$ and $\left(\delta^{15} \mathrm{~N}\right)$ provide important information on carbon sources and the trophic levels of species, allowing the reconstruction of the food web. Initial studies showed that $\delta^{13} \mathrm{C}$ in hydrothermal species was low compared to surrounding abyssal taxa, supporting the hypothesis of an organic autochthonous carbon source [RAU 79]. Since then, several studies on the isotopic composition of hydrothermal species have revealed that despite the low biodiversity, the structure of the food web may be complex. Generalist species (high variability in $\delta^{13} \mathrm{C}$ ) coexist with specialist species (low variability in $\delta^{13} \mathrm{C}$ ), supporting the hypothesis of resource partitioning in hydrothermal habitats [LEV 06]. These analyses also showed that the organisms with endosymbiotic bacteria were almost not consumed by other species, playing a less significant nutritional role than initially predicted [VAN 94]. This mass symbiotic production is 
likely reused by numerous scavengers in this environment. It seems that the hydrothermal food chain is based more on organic carbon fixed by free-living microorganisms, which are more accessible. The dominance of deposivore species compared to suspensivores suggests that attached microorganisms play a leading role in the nutrition of hydrothermal fauna. Research on the MAR revealed the presence of two independent trophic groups: one consisting of endosymbiotic mussels Bathymodiolus azoricus and their associated polychaetes (Branchipolynoe seepensis) and the second grouping the heterotrophic fauna [DEB 09]. The study also showed that the chemical composition of hydrothermal fluids influences the structure of the microbial community, therefore, affecting the carbon sources available. Abiotic conditions even cause changes in the proportion of symbionts in mussels [HAL 08].

Although still rarely used in these ecosystems, the analysis of fatty acids, which are specific biomarkers, can be useful to refine the results obtain through isotopic analyses. In addition, they help to differentiate the contributions from different microorganisms [COL 07]. In the hydrothermal environment, these biomarkers were used to measure the contribution of thiotrophic and methanotrophic bacteria in mussels with double symbioses [PON 98] and to assess the role of phytodetritus. The presence of lipid biomarkers of phytoplankton was detected, but in very low abundances among Bathymodiolus thermophilus. However, experiments have shown that the carbon source was insufficient to maintain good physiological conditions. Finally, these biomarkers have shown the low contribution of carbon from photosynthesis in the hydrothermal trophic network.

The role of hydrothermal production on surrounding ecosystems is difficult to quantify. The material from chemosynthetic sources is exported by nonnative predators of these ecosystems [MIC 02] and by the hydrothermal plume that can carry on fluids over long distances $(>\mathrm{km})$. Abundant communities of crustaceans (copepods and amphipods) have been observed in the water column above hydrothermal diffuse zones. Only 3\% of the total carbon that flows into deep benthic ecosystems would be derived from chemosynthetic production [JAN 95].

The characterization of the trophic network of hydrothermal ecosystems is still incomplete. Some compartments such as those of meiofauna and microorganisms are often absent from trophic studies. They do, however, represent important links toward higher trophic levels and significantly 
contribute to the complexity of the hydrothermal trophic chain. The functional role of different microbial communities in the transformation and degradation of organic matter remains to be defined.

\subsection{Distribution of fauna at different spatial scales}

\subsubsection{Ridges of the East Pacific}

Typical communities in the EPR and GSC, dominated by the Siboglinidae tubeworms and Alvinellidae, Bathymodiolin mussels and giant clams, range from the mouth of the Gulf of California to the Easter Island microplate with slight variations in composition, due to the temporal succession of populations and the isolation effect caused by transform faults. The dispersion of species, which occurs little-by-little along a linear ridge, is in fact interrupted by large breaks (faults or continental plates). More than 15 hydrothermal fields have been located and visited between $21^{\circ} \mathrm{N}$ and $23^{\circ} \mathrm{S}$. Despite their large latitudinal range, their depths vary only slightly, between 2,500 and $2,800 \mathrm{~m}$. The high regional diversity found on the EPR is linked to several factors including its geological age, high spreading rates, a high frequency of natural disturbance and the presence of large diffuse flow zones on the basaltic seafloor. One study shows that the community structure of Bathymodiolus thermophilus is similar between two fields separated by $1 \mathrm{~km}$ [VAN 02]; these two fields sharing more than $75 \%$ of their species. However, also with a high diversity, the structure of communities at a third site, situated $130 \mathrm{~km}$ away, showed little similarity with these other sites; this difference is not due to distance but rather due to the stage of activity of this senescent site.

On the same field, species distribution appears to be linked to the heterogeneity of the habitat. Active structures and diffuse emission zones are often colonized by different types of assemblages. A high level of similarity between fauna was observed between communities present in the same type of habitat on the EPR [GOV 05], the Juan de Fuca ridge (NEPR, [TSU 01]) and the MAR [VAN 00]. In the Guaymas Basin, four faunal assemblages were distinguished: two assemblages were associated with soft substrata (microbial mats and vesicomyids) and two with hard substrata on active structures (siboglinids and alvinellids). Many similarities were recorded between vent and seep common habitats in this region, suggesting a greater effect of the physico-chemical conditions in the absence of biogeographical barriers [POR 15]. 


\subsubsection{Ridges of the Northeast Pacific}

After 1977, other oceanic ridges were rapidly explored by geologists and biologists giving a more comprehensive view of the biogeography of hydrothermal ecosystems. The exploration of the Juan de Fuca in 1983, and that of the Explorer and Gorda ridges, revealed that the hydrothermal fauna was not cosmopolitan [TUN 85]. These Northeast Pacific ridges ${ }^{5}$ have been isolated from the EPR by the American continental plate for 28 million years, i.e. at the end of the Oligocene [TUN 96]. Consequently, few species are present on both sides of this plate, but many zoological and functional similarities are observed between the populations. Although few species are common to both (less than five), northern and southern populations share more than 20 genera.

The fauna of the NEPR is dominated by the tubeworm Ridgeia piscesae (siboglinidae). It forms extremely dense populations in diffuse emission zones [SAR 99c]. This species has distinct morphotypes, which vary according to the physico-chemical conditions of its habitat [URC 03]. The edifices are colonized by a variety of assemblages not found in basaltic microhabitats. Therefore, the high abundance of Paralvinella palmiformis is associated with the presence of Ridgeia on edifices. Another species, Paralvinella sulfincola, colonizes the walls of the newly formed chimney. By creating "isolating" marcasite crusts, this polychaete facilitates the implantation of palm worms ( $P$. palmiformis) on hot surfaces. Patelliform gastropods form gastropods of the genus Lepetodrilus form populations that can reach densities of more than 400,000 individuals $/ \mathrm{m}^{2}$. Scale worms (polychaete annelids Polynoidae), small predators and grazers of microbial mats are also found in large numbers. They are represented by several species similar to those on the EPR and belong to the genera Branchinotogluma and Lepidonotopodium. Large populations of microphagic pycnogonids are also associated with Siboglinidae. There are no large specialized carnivores but a species of spider crab Macroregonia macrochira has been observed within and outside hydrothermal sites as well as some Zoarcidae fish. Considered as being less extreme and more stable than sulphide edifice microhabitats, the diffuse flow areas, widespread over the basaltic seafloor, support a high species diversity [URC 03, BER 07]. A dozen active sites have been located between $41^{\circ}$ and $49^{\circ} \mathrm{N}$ on the Explorer, Juan de Fuca and Gorda ridges, at depths varying between 1,500 and $3,200 \mathrm{~m}$.

5 NEPR: North East Pacific Ridge. 


\subsubsection{Mid-Atlantic Ridge}

The MAR is a slow-spreading ridge $(1-3 \mathrm{~cm} / \mathrm{yr})$, with a pronounced axial valley. To the north, the Atlantic Ocean opened up during the Jurassic as the Tethys Ocean, then in the South, it widened into the Indian Ocean during the Cretaceous. The depth of the MAR varies greatly according to the proximity to hot spots. Emerging at Iceland, it exceeds a depth of $4,000 \mathrm{~m}$ in its tropical zone. The depth and composition of underlying rocks (basaltic or ultrabasic) have a significant influence on the composition of fluids and microbial populations.

In 1985, a camera towed from a surface vessel identified black smokers at a depth of $3,600 \mathrm{~m}$ at $26^{\circ} \mathrm{N}$. Submersible campaigns carried out later identified at this site (named TAG) and at $23^{\circ} \mathrm{N}$ (Snake Pit), at 3,480 m, a new type of hydrothermal population, very different to those in the Pacific and dominated by swarms of an unusual shrimp known as the "blind shrimp" and associated with a new species Rimicaris exoculata. In the adult stage, this shrimp has no eyes, but instead an unusual dorsal "eye", composed of a smooth cornea and a bilobed photosensitive and hypertrophied retina part. It has been suggested that this organ could be used to detect any possible infrared light emitted from hot sources [VAN 89]. Swarms of $R$. exoculata continually move on the walls of hydrothermal chimneys, and bathe in a diluted fluid with a temperature of less than $30^{\circ} \mathrm{C}$. Two other species Chorocaris chacei and Mirocaris fortunata belonging to the same family (Alvinocarididae) are also present at these sites but do not have comparable morphological adaptations, since they are associated with cooler habitats. Mussel assemblages, dominated by Bathymodiolus puteoserpentis, grow on hydrothermal edifices. Similar to their cousin on the GSC and EPR, they host the commensal worm Branchipolynoe seepensis also described at cold seeps in Florida. Studying the gill of these mussels reveals that they harbor a dual bacterial symbiosis that involves both sulfo-oxidizing bacteria and methanotrophic bacteria found in the same cells in the gill filaments [DUP 09]. The existence of these two symbionts increases the trophic plasticity of this animal. At the edge of these sites, there are filter-feeding and carnivorous species such as sea anemones, abundant populations of the worms Chaetopteridae and Ampharetidae and grazers of microbial mats such as brittle stars and some necrophages such as the gastropods Turridae. Crabs are represented by a single species, Segonzacia mesatlantica, much smaller than its Pacific 
counterparts $(40 \mathrm{~mm})$. One fish Zoarcidae, Pachycarathermophilum, is highly abundant at some sites. Since the first discoveries, many hydrothermal fields were located along the ridge from the north of the Azores to the south of the Equator. The depth of these sites varies from $800 \mathrm{~m}$ (Menez Gwen field close to the Azores) to 4,100 m (the Ashadze field situated at $\left.12^{\circ} 58^{\prime} \mathrm{N}\right)$.

Hydrothermal sites on the MAR are characterized by differences in depth and geological context, which influence the composition of communities. A continuum ranging from assemblages dominated by shrimps Rimicaris exoculata to assemblages dominated by Bathymodiolus mussels is present along this ridge. The first assemblages are associated with higher concentrations of metals and chlorinity, whereas the second assemblage is associated with a less extreme environment. Two species of mussels are present along the MAR: Bathymodiolus azoricus at shallow sites $(<2,500 \mathrm{~m}$, Menez Gwen, Lucky Strike, Rainbow) and Bathymodiolus puteoserpensis at deeper sites (> 3,000 m, Snake Pit, Broken Spur and Logatchev). They are, however, absent from the sites TAG and Ashadze-1.

The hydrothermal site Ashadze-1 can be distinguished from the others by the presence of a high abundance of anemones Maractis rimicarivora on hydrothermal edifices, near to diffuse emission zones [FAB 11]. Anemones are usually found on the edge of active hydrothermal sites. Low densities of shrimp Rimicaris exoculata may be attributed to the absence of hot emission zones at this site. However, polychaete worms of the family Chaetopteridae and necrophage species are very abundant. These observations together with the almost complete absence of engineer species living in symbiosis (with the exception of a few $R$. exoculata) suggest that this site could be in decline, thereby favoring species usually less common on active sites.

Variations in community structure observed along the depth gradient in the MAR may be associated with changes in the toxicity of fluids as well as the abundance of suspended particles [DES 00, DES 01]. In addition, the greater dispersion of non-hydrothermal species at the shallower Menez Gwen site is attributed to the presence of a lower hydrostatic pressure. The low similarity between the different shallow fields on the MAR $(<30 \%$ of species shared), and despite the absence of geographic discontinuity, suggests the presence of islands of fauna that have different physicochemical requirements. 


\subsubsection{Sites in the West Pacific}

To the west of the Pacific Ocean, there is a series of front and back-arc basins and active, underwater volcanoes: from north to south, the Okinawa Basin, Bonin ridge (Izu-Ogasawara), Mariana Basin, Manus Basin, Woodlarck Basin, North Fidji Basin, Lau Basin, Havre Basin and the Kermadec volcanic arc. These basins formed over several million years sunlike large oceanic ridges. The Okinawa Basin opened upon the Chinese ridge after 5 million years, the North Fidji Basin after 8 million years and the Lau Basin after 3 million years. These discontinuous structures, which extend from Japan to New Zealand, are separated by shelves and have different biogeographical entities.

The exploration of these basins began in 1986 with a photographic study of the Manus Basin. The images revealed not only active hydrothermal chimneys, but also biological populations dominated by large gastropods. The first dives took place in the Alvin submersible in the Mariana Basin on the axial ridge at a depth of $3,600 \mathrm{~m}$. They revealed an original fauna, different from that of the East Pacific. A new large gastropod Alviniconcha hessleri was found to dominate communities concentrated around vents [HES 91]. In this species, the gills can represent up to $40 \%$ of the body volume, the circulatory system is hypertrophic and the gut is unusually reduced compared with other species of the same family. Sulfo-oxidizing bacterial symbionts are present in the gills [STE 88]. Isotopic ratios reveal that A. Hessleri primarily subsists on symbiosis. The worm Paralvinella hessleri colonizes the walls of smokers and forms tangled of encrusted tubes. At the site periphery, there are mats of anemones Marianactis bythios, undoubtedly a carnivorous species, abundant populations of primitive barnacles Neoverruca brachylepadoformis as well as large populations of limpets Shinkailepa ssp. Around these sessile populations and on the basaltic seafloor, swarms of the shrimp Chorocaris vandoverae are present. The crab Austinograea williamsi and scale worms form the necrophage/carnivore level.

From this model, many variations along the accretion centers of the West Pacific can be observed. The zone currently with the most data is the Lau Basin and North Fidji Basin. These two basins are situated at the boundary between the Pacific and Indo-Australian plates. According to some authors [AUZ 88], these plates formed from the separation of a single ridge between 0.8 and 10 million years ago. The first explorations carried out by FrenchJapanese teams [DES 94] revealed populations dominated by two species of 
large gastropods. Alviniconcha sp., genetically similar to those found in the Mariana Basin, form large populations that are distributed close to vents. They are surrounded by populations of Ifremeria nautilei. As with Alviniconcha, the gills and circulatory system are hypertrophic and the digestive tract is reduced. Two types of symbiotic bacteria were observed in the gills, dominant sulfur-oxidizing bacteria, and those that oxidize methane [BOR 02]. Two bivalve species Bathymodiolus brevior and B. elongatus are present (B. brevior only in the Lau Basin), and these populations are situated on the external margins of the vent community. Alviniconcha $s p$. has a very high growth rate and carbon fixation rate is also one of the greatest measured to date. In Ifremeria and Bathymodiolus [HEN 08], the carbon fixation rate is an order of magnitude less than that of Alviniconcha. Populations of filterfeeders such as barnacles, brisingid starfish and carnivorous sponges were also observed at the edge of these sites.

Here, it is difficult to detail all the differences between the fauna in the different basins of the West Pacific (see [DES 06b]). The Okinawa Basin contains soft and rocky substrata at sites situated at depths varying from 640 to $1,500 \mathrm{~m}$. On hard substrata, mussels dominate (Bathymodiolus platifrons and B. japonicus) and several species of Siboglinidae tubeworms belonging to the genera Lamellibrachia and Alaysia form populations at the base of chimneys where the worm Paralvinella hessleri extends its tubes. Large colonies of the squat lobster Shinkaia crosnieri are close to vents in densities exceeding 550 individuals $/ \mathrm{m}^{2}$. Stable isotope studies have shown that this animal feeds off chemoautotrophic filamentous bacteria either from epibionts or microbial mats. Filter feeders on the periphery include diverse species of barnacles. In sedimentary environments, three burrowing species of clam Calyptogena solidissima, $C$. okutanii and $C$. nankaiensis dominate the community.

The system of the volcanic arcs Izu-Ogasawara (Bonin) and Mariana is a convergent margin that extends from Tokyo to the Guam island. Many underwater volcanoes are distributed along this system of arcs. The depths, chemistry of fluids and substrata are very heterogeneous at these sites that extend from the photic zone to a depth of $1,500 \mathrm{~m}$. In shallower zones, corals and hydrothermal fauna intermingle. The fauna is dominated by mussels Bathymodiolus septemdierum and Gigantidas horikoshii associated with the scale worm Branchipolynoe pettibonae. The flatfish Symphurus orientalis is present in large populations and many species of barnacles (Neoverruca) colonize the periphery. 
Some populations of Siboglinidae and the species Lamellibrachia satsuma are found on the volcano Nikko at depths varying from 430 to $600 \mathrm{~m}$. This species is also present in the Kagoshima bay at a depth of around $100 \mathrm{~m}$. Further south, between the Lau Basin and New Zealand, along the Havre Basin emerge a series of active volcanoes (Kermarec arc) whose summits vary from 300 to $1,200 \mathrm{~m}$ high. Research on hydrothermal plumes indicates that seven of the 12 volcanoes studied are likely to be active. The populations appear to be dominated by a species of mussel Gigantigas gladius whose shell may exceed $30 \mathrm{~cm}$ in length.

\subsubsection{Ridges in the Indian Ocean}

Due to their isolation, ridges in the Indian Ocean have barely been explored. During the summer of 2000, the Japanese Kairei vessel deployed the $\mathrm{ROV}^{6}$ Kaiko on a segment of the Central Indian Ridge ${ }^{7}$ situated to the north of the Rodriguez Triple Junction (2539' S). Two active hydrothermal fields, Kairei and Edmond, separated by $160 \mathrm{~km}$, were discovered. The hydrothermal field Kairei $(2,415-2,460 \mathrm{~m})$ is located at $25^{\circ} 19^{\prime} \mathrm{S}, 70^{\circ} 02^{\prime} \mathrm{E}$. At least seven active sites including black smokers have been observed, with edifices reaching up $10 \mathrm{~m}$ in height. The maximum temperature measured was $360^{\circ} \mathrm{C}$, with a $\mathrm{pH}$ of 3.4 . The hydrothermal field Edmond $\left(23^{\circ} 52^{\prime} \mathrm{S}\right.$, $69^{\circ} 35^{\prime} \mathrm{E} ; 3,290-3,320 \mathrm{~m}$ ) was discovered at approximately $160 \mathrm{~km}$ from the field Kairei. Hydrothermal fluids $\left(273-382^{\circ} \mathrm{C}\right)$ form four sites on the Edmond field. These exhibit a higher chlorinity than that of ambient seawater, making them the hottest brines collected on the ridges. The invertebrate community on the Kairei field is characterized by central populations on black smokers, dominated by dense swarms of shrimp (Rimicaris kairei) that colonize fluids at $10-20^{\circ} \mathrm{C}$ and a cold peripheral zone $\left(1-2^{\circ} \mathrm{C}\right)$ dominated by anemones (Marianacti ssp.). In intermediate zones, at the base of the shrimp swarms, assemblages of several hundred mussels (Bathymodiolus aff. brevior) and gastropods (Alviniconcha n. sp. and scaly foot vetigastropods) are found. Brachyuran crabs (Austinograea rodriguezensis), flat worms of the class turbellarians, nemertean worms and a second species of shrimp (Chorocaris $n . s p$ ) are often abundant in the transition zone between the anemones and shrimp. Other gastropods (limpets and provannids), polynoid worms (Branchinotogluma $n . \quad s p$.) and

6 ROV: remotely operated vehicle.

7 CIR: Central Indian Ridge. 
archinomids (Archinome sp.) as well as populations of cirriped crustaceans of the genus Neolepas are also present in this intermediate zone. Vesicomyid shells were collected $1 \mathrm{~km}$ from the Kairei field but no living individuals were found so far [HAS 01].

The fauna on the Edmond field is a subgroup of those found in the Kairei field. The biomass is dominated by dense swarms of shrimp $R$. kairei and the peripheral zones are colonized by anemones. Cirriped crustaceans, scaly foot gastropods, archinomid polychaetes, nemertians and turbellarians are absent.

The scaly foot vetigastropod Peltospiridae, still being described, has many interesting anatomical adaptations [WAR 03] including a reduced or absent opercula and the presence of a foot covered with sclerites. The esophageal gland is between 10 and 1,000 times larger than in other gastropods, whereas the rest of the gut is 10-100 times smaller; the circulatory system is hypertrophic to supply the gills and the esophageal gland and the radula is much smaller. Several studies [GOF 04] reveal that $\gamma$-proteobacteria colonize cells of the esophageal gland and their genomes contain all the functions of chemoautotrophic symbionts of hydrothermal organisms. Studying the ratio of natural carbon isotopes confirmed that autotrophy is present in these symbionts.

A Japanese campaign [NAK 12] found two other sites situated between 18 and $20 \mathrm{~S}$ on the Central Indian Ridge at a depth of 2,600-2,750 m. The two sites called Dodo and Solitaire have a similar fauna to that described on the Kairei field. Dense populations of shrimp Rimicaris kairei and Mirocaris indica were observed on active structures. Zonation patterns were observed with populations of worms as well as Alviniconcha $s p$. and scaly foot vetigastropods distributed along hydrothermal diffuse emission zones. Bathymodiolus mussels with large populations of limpets Lepetodrilidae are found further from the chimneys, and at the periphery, Phymorhynchus necrophages and at least two species of filter-feeding cirripeds Neolepas and Eochionelasmus were observed. A. rodriguezensis and a new species of shrimp Chorocaris were present close to the gastropods and mussels, whereas only some individuals of $R$. Kairei were observed at this site. Macrourid fish, Marianactis anemones, Munidopsis squat lobsters and holothurians are found outside the zones colonized by hydrothermal fauna. One remarkable discovery is the presence of alvinellid polychaetes. This family was never recorded outside the Pacific Ocean and its presence reinforces the proposed biogeographical link between the fauna in the west Pacific and that in the Indian Ocean. In January 2011, an expedition by RRS 
James Cook located four hydrothermal fields on the ultra-slow South West Indian Ridge ${ }^{8}$ at $37^{\circ} 47^{\prime} \mathrm{S}-38^{\circ} 28^{\prime} \mathrm{S}$ at a depth of $2,750-2,840 \mathrm{~m}^{9}$. The faunal composition appears quite similar to those at other Indian ridge sites, with the exception of the presence of populations of the Kiwaidae "yeti crab", Kiwan. sp., which are very different from species in the West Pacific [ROT 13] as well as white holothuria on the periphery of mussel beds. This suggests that the characteristics of hydrothermal fluids (and therefore their quality and availability in microhabitats) rather than geographic affinities would play a predominant role in the structure of these communities.

\subsubsection{Ridges in the Southern Ocean}

With the development of research ROVs, the exploration of ridges has reached Polar Regions, which up until now have been infrequently visited. Active sites were located in the Arctic Ocean at depths of 700-750 m to the north of the Jan Mayen Island on the Mohn Ridge. There populations are dominated by non-specialized bathyal species despite being at similar depths to the Menez Gwen vent field in the Azores where hydrothermal species dominate. However, it appears that bathyal fauna partly subsists of carbon from chemosynthetic origin [SWE 13]. In the Southern Ocean, sites visited on the East Scotia Ridge ${ }^{10}$ at a depth of 2,600 m provide new information about the biogeography of this region and its association with other biogeographical provinces [ROG 12]. The Scotia Sea is surrounded by a series of ridges and islands (Scotia arc), and reach depth of approximately $3,000 \mathrm{~m}$. The ESR has a length of approximately $500 \mathrm{~km}$, and its expansion began approximately 15 million years ago. It has an accretion rate of $70 \mathrm{~mm} / \mathrm{yr}$. In 2010, the English ROV Isis located two hydrothermal fields, the first at $60^{\circ} 02^{\prime}$ 'S known as Devil's Punchbowl $(2,400 \mathrm{~m})$ and the second at $56^{\circ} 5^{\prime} \mathrm{S}$ called Mermaid's Purse $(2,600 \mathrm{~m})$. The temperatures of the hydrothermal fluids are very high $\left(352-382^{\circ} \mathrm{C}\right)$ and diffuse emission zones, where temperatures vary from 3 to $20^{\circ} \mathrm{C}$, are present. Ambient temperatures vary from -0.11 to $-1.3^{\circ} \mathrm{C}$. Although sample studies are still underway, general information about the population distribution and composition is already available [MAR 12].

\footnotetext{
8 SWIR: South West Indian Ridge.

9 www.thesearethevoyages.net/jc67/nov30.html.

10 ESR: East Scotia Ridge.
} 
The hottest parts of hydrothermal edifices are covered by anhydrite deposits without fauna and only some microbial mats are visible. The adjacent parts are occupied by large populations of the crab Kiwan. sp. [ROT 13] whose size decreases as the distance from vents increases, whereas densities increase from 65 to 4,017 individuals $/ \mathrm{m}^{2}$. The "yeti crabs" closest to the vents have filaments of epibiontic bacteria on the ventral side of their carapace, whereas individuals further away from this fluid do not. The only fauna associated with these populations is a new species of limpet belonging to the genus Lepetodrilus. At the base of the structures, a large peltospiroid gastropod forms very dense populations around the "yeti crabs" $\left(>1,000\right.$ individuals $\left./ \mathrm{m}^{2}\right)$. Severals stalked that barnacles Vulcanolepasn. $s p$. are observed around the periphery and reach densities of approximately 900 individuals $/ \mathrm{m}^{2}$ associated with Lepetodrilusn. $s p$. Several species of actinostolid anemones and pycnogonids (Sericosura and Colossendeis) are also present. Predators are represented by seven arm starfish and an undetermined octopus.

\subsubsection{Cayman Ridge}

The Mid-Cayman Spreading Center ${ }^{11}$ (MCSC) is an ultra-slow ridge with a length of approximately $110 \mathrm{~km}$, situated in the Cayman Basin, in the Caribbean Sea. It spreads at a speed of $1.5 \mathrm{~mm} / \mathrm{yr}$ and has been active for 49 million years. This is the deepest accretion center known in the world's oceans, the depth of its axis being between 4,200 and $6,000 \mathrm{~m}$. A chemical signal was detected north of the ridge, on a neo-volcanic formation, and active chimneys were located at $18^{\circ} 32.785^{\prime} \mathrm{N}$ and $81^{\circ} 43.080^{\prime} \mathrm{W}$ at a depth of $4,960 \mathrm{~m}$. The site was named in honor of William Beebe, the first naturalist to observe a bysso-pelagic fauna in situ (Beebe Vent Field or BVF). The BVF is a mound of polymetallic sulfides with a diameter of $80 \mathrm{~m}$ and height of $50 \mathrm{~m}$ on top of which are active chimneys [CON 12]. The fauna is dominated by dense $\left(>2,000\right.$ individuals $\left./ \mathrm{m}^{2}\right)$ swarms of shrimp Rimicaris hybisae [NYE 13] which are found on the walls of the chimneys. These shrimps have the same adaptations and epibioses as $R$. exoculata from the MAR. Populations of undetermined anemones are spread over the peripheral zones of the site.

A second site (Von Damm Vent Field or VDVF) was found and studies were done on the Dent vent, a structure rising $2,700 \mathrm{~m}$ above the axis of the ridge at

11 MCSC: Mid-Cayman Spreading Center. 
$13 \mathrm{~km}$ to the west (at a depth of 2,294 m). This site corresponds to a hydrothermal mound with a diameter of $100 \mathrm{~m}$ and a height of $30 \mathrm{~m}$. At the summit, hydrothermal vent releases a light fluid with a temperature of around $18^{\circ} \mathrm{C}$. Zoarcidae fish (see Pachycara) as well as squat lobsters have been observed but have not yet been sampled. Beds of Mytilidae shells and empty Siboglinidae tubes were present at approximately $400 \mathrm{~m}$ to the south of the VDVF field, which reveals the presence of recent activity. Some data available for MCSC show that despite the isolation of this zone, it shares many similarities with the fauna found at deep hydrothermal sites at the MAR.

\subsubsection{Biogeography of deep hydrothermal vents}

Hydrothermal communities are composed of a reduced group of species capable of withstanding the harsh environmental conditions and to exploit chemosynthetic microbial production. Most of the species described in this environment have not been reported in the surrounding abyssal area, hence the high level of endemism encountered in these ecosystems. The concept of biogeographic provinces is used to highlight the result of processes such as selection, extinction, dispersion, etc., acting on faunal distribution on long temporal scales. Associations between hydrothermal species that are distributed over linear structures and consisting of endemic taxa would, therefore, be models that are particularly adapted to biogeographic studies, provided that hydrothermal fauna evolved independently of other ecosystems based on microbial chemosynthesis, which is the least controversial hypothesis.

Moreover, for the conclusions to be unequivocal, a set of consistent taxonomic data and sampling that covers all geographic zones must be obtained, which is not yet the case. Zones at high latitudes have been less explored and may provide corridors for the dispersion of many vent taxa. In addition, data from the Indian Ocean are still patchy (including data from isolated basins such as the Andaman basin, still unexplored), those in the North Atlantic are limited to zones between $45^{\circ} \mathrm{N}$ and $4.48^{\circ} \mathrm{S}$ with the exception of the recent studies on the Mohn ridge and the ESR. Taxonomic information, whether it is based on morphological and/or genetic information, is still incomplete and heterogeneous. Therefore, the information available on the biogeography of hydrothermal communities is still incomplete to draw an accurate large-scale distribution portrait of vent fauna. 
The most recent global study [MOA 12], based on the analysis of faunal distance $^{12}$ (Jaccard distances) of a genus/site matrix using the network theory, outlines five robust groups of hydrothermal fields:

- EPR, GSC, PAR ${ }^{13}$;

- Northeast Pacific;

- West Pacific basins;

- Indian ridges;

- MAR.

Interestingly, results on the connectivity between provinces reveal the central position of East Pacific basins. The fauna of the MAR has no direct relationship with EPR but is linked to the Pacific via the Indian Ocean. This central position is reinforced if we focus on the main taxa (annelids, mollusks and crustaceans). In their recent publication on ESR sites, Rogers et al. [ROG 12] propose the existence of a sixth biogeographical province that groups the Antarctic ridge sites.

\subsection{Faunal microdistribution and interactions}

A hydrothermal site (also known as a field) is a zone with more or less localized hydrothermal emissions. It includes several active hydrothermal structures and also diffuse emission zones. Fauna assemblages colonize narrow mixing gradients between hydrothermal fluids and seawater, on hard substrataor in thick sediment layers. These organisms subsist at this physicochemical interface due to their capacity to withstand the harshness of the environment but also to sustain their trophic requirements.. The characterizations of physico-chemical conditions in the habitats of hydrothermal species are still relatively limited, primarily due to the difficulty in carrying out in situ measurements close to these organisms. Only some factors such as temperature and oxygen are relatively "easy" to measure in the deep sea.

12 The most recent information for the Indian Ocean (CIR and SWIR), as well as those for ESR, the Mohn ridge and the MCSC,is not taken into account in this study.

13 Pacific Antarctic Ridge. 
Initial studies outlining the concept of zonation date back to the $1980 \mathrm{~s}$. The studies describe that species are distributed around active hydrothermal structures depending on their distances from vent emissions [HES 83]. EPR communities are distributed along an environmental gradient: siboglinid polychaete worms are found in high diffuse flow zones $\left(\leq 25^{\circ} \mathrm{C}\right)$, bivalves in moderate flow zones $\left(\leq 10^{\circ} \mathrm{C}\right)$, whereas filter-feeding species colonize low flow peripheral zones. A similar zonation is also observed at other sites on the Pacific Ridge and on the MAR, where less tolerant species colonize the periphery, whereas the most active zones are colonized by more tolerant pioneer species. Less extreme zones also provide a refuge for larvae, juveniles as well as spawning females [TYL 99]. A recent observation rather showed that for the shrimp Rimicaris exoculata, males instead of females appear to colonize the less active zones.

\subsubsection{Environmental conditions}

Environmental conditions affect the distribution of organisms, influencing the diversity and modifying the structure of communities. A species becomes absent from a zone where the abiotic factors exceed its tolerance limit (e.g. temperature) and from an environment that cannot meet its requirements (e.g. nutrients). Even if all factors, but one, are found within the tolerance limits, the species will be eliminated or absent. Environmental conditions also influence the dispersion, recruitment and fixation of larvae. The frequency and intensity of environmental fluctuations may exceed the tolerance limits, affect recruitment, modify the quantity and quality of food available and even initiate succession. Recent studies on the EPR show that the species distribution at a site is complex and would result from the combination between the temporal variability in larval installation [MUL 98], competition between the first colonizers [MUL 00], predator-prey relationships [MIC 02], physiological limits and nutrient gradients [LEN 08].

\subsubsection{Temperature}

Temperature fluctuations at scales varying from seconds to hours and sudden changes in chemical conditions result from the turbulent mixing of hot fluids with the surrounding cold seawater as well as from the influence of biotic and abiotic processes on this mixing. The community structure is greatly influenced by temperature, which, locally, is a good "proxy" for the chemical composition of hydrothermal fluids [SAR 99a]. 
The hottest zones are exploited by species that can tolerate high temperatures and significant environmental fluctuations, whereas habitats at lower temperatures, characterized by a greater stability, are colonized by less tolerant species. Several studies highlight the reduced diversity at in the hottest areas of the ecosystem. Some species have a broader niche [CUV 11] which reflects their capacity to move between different microhabitats as suggested for the shrimp Rimicaris exoculata [RAV 03] or for gastropods in the Lau basin [POD 09].

Several examples support the fact that species colonize zones where temperatures are below their tolerance limits which allow them to survive to significant and sudden fluctuations in environmental conditions [BAT 10]. Thus, the polychaete worm Paralvinella sulfincola, which occupies newly formed chimney surfaces, has a much greater thermal preferendum than the temperatures measured in its habitat. In addition, the result of one study showed that the spatial distribution of species in the Lau basin was influenced by different thermal tolerances [POD 09]. The gastropods Alviniconcha $s p$. and Ifremeria nautilei are present close to fluid sources, whereas the less tolerant mussel Bathymodiolus brevior colonizes peripheral zones.

Physiological adaptations play an important role in faunal distribution patterns [FIS 90]. The distribution of Riftia pachyptila and Calyptogena magnifica on the EPR would be determined by their physiological tolerance as well as their strict requirements for hydrogen sulfide to sustain their endosymbiotic bacteria [CHI 92]. Furthermore, behavioral adaptations also participate to the adaptation of vent species by allowing organisms to survive in fluctuating environmental conditions. For example, alvinellid polychaetes regulate the temperature in their habitats by moving their gills [CHE 93].

\subsubsection{Sulfides}

Hydrogen sulfide $\left(\mathrm{H}_{2} \mathrm{~S}\right)$ is toxic to aerobic organisms as it inhibits mitochondrial respiration and the binding of oxygen to most hemoglobins [FEL 85]. However, the presence of $\mathrm{H}_{2} \mathrm{~S}$ in fluids is also linked to the availability of food. The fauna associated with these emissions has developed different detoxication mechanisms that allow them to carry out aerobic respiration regardless of whether $\mathrm{H}_{2} \mathrm{~S}$ is present or not [MAR 97]. Some species with sulfur-oxidizing symbionts such as Riftia pachyptila have a particular type of hemoglobin that allows the transport of sulfides to their 
symbionts by reversibly binding them [ZAL 98]. Furthermore, the presence of many mitochondria and lysosomes in the gills of some polynoid species and alvinellids allow them to withstand high concentrations of sulfide in their environment [HOU 00].

This ability to tolerate $\mathrm{H}_{2} \mathrm{~S}$ influences the composition and spatial distribution of hydrothermal communities [LUT 01, SAR 99c]. Whereas some species appear to be adapted to habitats rich in $\mathrm{H}_{2} \mathrm{~S}$, others are limited to diffuse emission zones. For example, the pioneer species, Tevnia jerichonana, on the EPR colonizes habitats with higher concentrations of $\mathrm{H}_{2} \mathrm{~S}$ than in the case of Riftia pachyptila, the species that follows in the proposed biological succession model [LUT 12, SHA 98]. The speciation of sulfides, and therefore their bioavailability, varies significantly from one habitat to another. In the Lau basin, the gastropod Alviniconcha spp. colonizes habitats with higher concentrations of $\mathrm{H}_{2} \mathrm{~S}$ than the other two pioneer species at this site (Ifremeria nautilei and Bathymodiolus brevior [POD 09]). The presence of high concentrations of iron may reduce the availability of $\mathrm{H}_{2} \mathrm{~S}$ [LUT 01] and constrain the distribution of some species such as mussels and siboglinids [GOV 05]. $\mathrm{pH}$ favors $\mathrm{H}_{2} \mathrm{~S}$ over HS increasing its ability to diffuse through membranes and therefore, its toxicity [VIS 91].

The distribution of nematodes and copepods, which usually dominate the meiofauna, varies according to temperature and/or concentrations of sulfides and their diversity is higher in zones where sulfide concentrations are lower [GOL 10b]. Dirivultid copepods are present in a wide range of environmental conditions [GOL 10a], whereas tisbids are restricted to stricter conditions [IVA 11]. On the Juan de Fuca Ridge, only the copepod Stygiopontius quadrispinosus is associated with the higher temperature environments [TSU 03a]. Moreover, it was recently shown that adult and larval copepods may not be found in the same microhabitats [SAR in press].

\subsubsection{Oxygen}

Variations in oxygen are extreme in the hydrothermal environment and organisms colonize the interface between anoxic (hydrothermal fluid) and oxic (seawater) conditions. Some taxa are physiologically well adapted to frequent fluctuations in oxygen [ARN 98] whereas others are less so, hence its influence on species distribution. A study at $9^{\circ} \mathrm{N}$ (EPR) reveals that oxygen concentrations were less than $120 \mu \mathrm{M}$ within the habitats and that 
above $10^{\circ} \mathrm{C}$, the fluids were totally anoxic [LUT 12]. Oxygen concentrations in the habitat of Tevnia jerichonana, following a series of volcanic eruptions, reveal that this pioneer species can colonize habitats characterized by low oxygen concentrations, while Riftia pachyptila and Bathymodiolus thermophilus are found in more oxygenated environments. Similarly, the mussel Bathymodiolus brevior in the Lau basin lives in more oxygenated conditions whereas species associated with warmer zones, Alviniconcha spp. and Ifremeria nautilei, colonize less oxygenated zones [LUT 12]. Several physiological adaptations increase the capacity of species to withstand low concentrations of oxygen [CHA 04, HOU 07].

\subsubsection{Metals and radioactivity}

The hydrothermal environment harbors natural concentrations of heavy metals and toxic radioelements, which may influence species distribution. The accumulation of metals by organisms depends on their bioavailability in surrounding waters and the capacity of organisms to manage the presence of these metals. Therefore, some species appear to have developed a high tolerance to high metal concentrations and possess high concentrations in their tissues [COS 08]. With regard to radioelements, the results show different trends depending on the site, position of organisms in the mixing zone and the trophic regime of the species. Significant accumulation, much higher than in species from other marine habitats, can be found in their tissues [CHA 09]. The tolerance of hydrothermal species to these abiotic constraints probably has a role to play in their realized spatial distribution.

\subsubsection{Hydrothermal fluid flow}

Fluid flow is a complex variable that integrates variations in temperature, availability of hydrogen sulfide and other chemical elements and particles. Changes in fluid flow can also affect the overall metabolism of species, as well as growth, reproduction and colonization processes. Fluid flow also affects the availability of food resources by altering the input of particulate matter and the uptake of chemicals by microorganisms. The lower abundance of siboglinid communities south of the EPR $\left(13^{\circ} \mathrm{N}\right)$ was correlated with lower hydrothermal activity [FUS 87] whereas on the Juan de Fuca Ridge (NEPR), an increase in activity caused visible changes in the distribution of fauna [SAR 97]. The development of dense aggregations of shrimp on the MAR was associated with the presence of high emission zones [COP 97] and the distribution of fauna assemblages on the Eiffel Tower edifice (MAR) is associated with the proximity to fluid emissions 
[CUV 09b]. On the Juan de Fuca ridge, some species of copepods are dominant in high flow zones, whereas low abundances are found in senescent zones [TSU 03a]. At the community level, high flow zones are more associated with low diversity, whereas low flow zones, which are less restrictive, are home to the highest diversity [SAR 97, SAR in press].

Results of a study carried out by Kelly et al. [KEL 07] on the Juan de Fuca ridge suggest that the properties of fluids influence the installation and colonization of hydrothermal species. The dispersion of larvae over great distances despite their reduced swimming capacity questions the role of hydrothermal emissions and hydrodynamic processes on their distribution [KIM 98]. Changes in fluid flow may even initiate species succession in some hydrothermal communities [SAR 97, SHA 98]. While species succession in diffuse flow areas is relatively easy to predict, the growth of hydrothermal communities after reactivation of a site is still poorly understood. An increase in fluid flow may cause a variety of different assemblages, reflecting the patchiness of emissions across a site [LEB 06].

\subsubsection{6. $\mathrm{pH}$}

$\mathrm{pH}$ influences calcification/decalcification processes in marine organisms and has severe consequences on metabolism and reproduction. It also influences the acquisition of nutrients, speciation and the bioavailability of metals. Changes in $\mathrm{pH}$ can have significant impacts on metabolism and a too acidic $\mathrm{pH}$ can even be lethal to most organisms. Hydrothermal organisms in warmer zones may experience acidic $\mathrm{pH}$, as in the case of Alvinella pompejana ( $\mathrm{pH}$ of approximately 4) on the SEPR. Few studies have focused on the direct effects of $\mathrm{pH}$ on the distribution of hydrothermal fauna since this variable is correlated to most other environmental variables. $\mathrm{pH}$ significantly influences the distribution of some taxonomic groups, such as copepods [IVA 11] and nematodes [SAR in press], and a linear relationship between $\mathrm{pH}$ and diversity has been observed in meiofauna on the EPR [GOL 10b]: a higher $\mathrm{pH}$ favors diversity.

\subsubsection{Hydrodynamic and tidal processes}

Variations in hydrodynamic processes affect the structure of benthic communities at different spatial and temporal scales. On a small spatial scale, these processes have an influence on competition and predation rates, the transport and deposition of particles and larvae as well as oxygenation. Ocean currents play an important role in the dispersion of pelagic larvae and 
juveniles [MUL 95] as well as nutrients. Cuvelier et al. [CUV 11] suggest that the distribution of small mussels on the Eiffel Tower edifice (MAR) was significantly influenced by the orientation of this structure, the side most exposed to currents being colonized by a greater abundance of small individuals. Thus, the presence of relief generates currents that create microhabitats and increase the spatial heterogeneity [KIM 98] favoring the installation of filter-feeding communities. The role that the currents play on the structure of hydrothermal communities is not fully understood. As larvae cannot swim great distances, their dispersion would be insured by deep currents [TYL 99]. In fact, tidal currents and hydrothermal plumes may help transport larvae several kilometers [MUL 95]. Moreover, spatio-temporal variations in currents may influence the recolonization of new sites after an eruption [MUL 10].

The flow of inorganic and organic particles close to hydrothermal vents is an important factor both in terms of toxicity and nutrition. Some benthic organisms are particularly sensitive to water turbidity. High concentrations of particles may have adverse effects by clogging the filtration system and the surfaces involved in gaseous exchanges. Thus, the high particle loads found at the Rainbow hydrothermal site were considered as a factor that may explain the low abundance of Bathymodiolus mussels [DES 00].

Several studies reveal that emissions of hydrothermal fluids are affected by tidal signals [CHE 91, TIV 02]. This suggests an impact on the distribution of fauna by modifying the nature and composition of hydrothermal fluids. Recently, a study on the activity of siboglinids on the Juan de Fuca ridge shows that the rhythm at which they enter and exit their tubes is directly linked with tidal rhythms [CUV 14].

\subsubsection{Depth}

The effect of pressure on the spatial distribution of marine communities is significant. Since biochemical reactions are usually sensitive to differences in pressure, animals at great depths have developed metabolic and physiological adaptations to survive [SOM 92]. At hydrothermal vents, the composition of communities varies from one depth to another. For example, on the MAR, Bathymodiolus mussel assemblages dominate shallower sites, which are also home to a greater abundance of abyssal species. The deepest sites are rather dominated by shrimp assemblages [DES 01]. Although the influence of photosynthesis is virtually absent in the trophic network of deep 
hydrothermal environments, its influence may be notable at some shallower sites.

\subsubsection{Type of substratum}

The nature, texture, orientation, position, slope and heterogeneity of substrata influence the structure of benthic communities. The succession model proposed by [SAR 97] for edifice communities on the Juan de Fuca ridge takes into account the evolution of the substratum. Therefore, pioneer communities colonize newly formed substrata, characterized by a high permeability and the presence of more elevated fluid emissions, whereas climax communities are found on less porous and more stable substrata. Substrata also play a role in species distribution and density. Thus, the abundance of meiofauna in siboglinid assemblages on the EPR is associated with the amount of sediment trapped in the tubworm bushes [GOL 07]. The distribution of dirivultid copepods would also be influenced by the type of substratum since these organisms are preferentially found on hard ones such as sulfide or basalt edifices [GOL 10a]. However, the diversity of nematodes, associated with Bathymodiolus mussel assemblages on the SEPR, is greater in soft substratum communities [ZEK 06].

\subsubsection{Nutrients}

The quantity and quality of available food may influence the reproduction and recruitment of benthic invertebrates and modify the composition, density and abundance of communities on hard substrata. This observation is particularly true for hydrothermal ecosystems where high concentrations of food support an exceptionally large biomass for the deep-sea environment [SAR 99b]. Several authors have shown that the physico-chemical conditions of the hydrothermal environment influence the food available to organisms and that the composition of particulate organic matter varies according to time and space [LEV 05]. Nutrients are distributed heterogeneously and biofilms partially cover the different surfaces available. A study along the thermal gradient revealed a higher abundance of microorganisms closer to emissions [SIE 99]. Thus, spatial variations in flow intensity may influence the resources used by the fauna [LIM 07]. This spatialization of resources certainly has an impact on the distribution of vent species. An increase in the density of abyssal megafauna around active sites suggests that their distribution and abundance are strongly linked to the increased availability of food. 


\subsubsection{Habitat heterogeneity}

Assemblages of siboglinids, alvinellids and bathymodiolin mussels provide a protected habitat for larvae, juveniles and small species. These engineer species create three-dimensional habitats with gradients in environmental conditions, thereby reducing environmental stress and favoring the local and regional diversities [KEL 08]. These structuring species also contribute to the concentration of organic particles [SAR 02]. In siboglinid assemblages of the Pacific, species richness is positively correlated with the total area provided by the tubes of the worms [GOV 05]. On a smaller scale, colonies of cilia and microbial mats also form threedimensional microstructures that favor the colonization of juveniles and meiofauna in high abundances [KEL 08, KOU 07].

\subsubsection{Natural disturbances}

Catastrophic events may severely affect the structure of benthic communities, depending on the severity and frequency of the disturbance. These disturbances may cause partial or total destruction of a community and provide new spaces to be colonized. Major events such as volcanic eruptions and disturbances related to plate tectonics regularly affect hydrothermal ecosystems. On fast-spreading ridges, such as the EPR, significant tectonic and magmatic events occur [HAY 91] whereas on slowspreading ridges, these events are rarer [DZI 04]. They may completely destroy a habitat or cause the opening or closing of new conduits. On a local scale, the collapse of hydrothermal walls, changes in fluid composition and modifications of fluid flow represent sources of disruption for these communities. These more or less regular disruptions may explain the high productivity and low diversity of hydrothermal ecosystems [KIM 98].

\subsubsection{Biotic interactions}

Benthic species are often restricted to only part of their potential niche due to the constraints imposed by other organisms. Thus, the environmental conditions determine the succession of species capable of colonizing the substratum but their success and the final structure of communities are also governed by biological interactions. The level of species interactions will vary according to the degree of physical stress [CON 75]. Results from a transplant experiment of hydrothermal fauna between active and inactive areas on the EPR reveal that species distribution was not only limited by 
environmental factors but also by the food available to species in inactive areas and by biotic interactions in active areas [MUL 09]. Competition, predation and grazing are the main biological interactions that control the structure and diversity of benthic communities [GAG 91].

\subsubsection{Competition}

Competition for space in the redox transition zone is high due to the dependence of organisms on the resources brought by hydrothermal fluids. The mixing zone, where both hydrogen sulphide and oxygen necessary to the fauna are present, is characterized by high density of fauna favoring competition. A decrease in hydrothermal activity in the GSC caused significant community changes. Bathymodiolin mussels were favored to the detriment of siboglinids probably due to their greater capacity to exploit low sulfide concentrations [HES 88]. Mixotrophy and their ability to move would also give the mussels a competitive advantage against other species since they can adapt, at least temporarily, to disruption in vent fluids and even senescence. This may partly explain their dominance at the end of succession on the EPR.

On the MAR, the greater requirement for chemical compounds of large mussels may explain their migration toward areas of higher fluid flux and the size segregation observed on edifices [COM 98]. The superposition of isotopic signatures of two species of shrimp (Mirocaris fortunata and Chorocaris chacei) on the Eiffel Tower edifice on the MAR may indicate that they are in competition for nutrients [DEB 09]. Nevertheless, the habitats colonized by $M$. fortunata have greater temperature ranges and iron concentrations than $C$. chacei, which is restricted to habitats with slightly higher temperatures [SAR 15].

On the Juan de Fuca ridge, several accompanying species have similar isotopic signatures, which suggest that they use the same food sources [BER 07]. The success of Lepetodrilus fucensis that may be present in extremely high densities near the emissions is probably linked to its capacity to exploit different food sources through different feeding modes. Recent experiments suggest that this species may exert a high pressure on these resources, causing the decrease in abundance of other species [LEL, thesis in progress]. A behavioral study of Paralvinella sulfincola reveals that its aggressive behavior ensures that it has privileged access to nutrients [GRE 06] and would explain its dominance in the most extreme colonized areas on the 
Juan de Fuca ridge. Other studies show that competition seems to drive less competitive species toward peripheral zones [MAR 02]. Competition may play a role in the exclusion of some gastropod species by leading them toward poorer habitats [BAT 05]. Finally, the distribution of the three dominant species of megafauna in the Lau basin (Alviniconcha spp., I. nautilei and B. brevior) may be linked to interspecific interactions [POD 09].

The influence of competition on the structure of communities is not limited to adult stages. On the SEPR and MAR, Bathymodiolin mussels appear to prevent recruitment of invertebrates. Thus, an inverse relationship was observed between mussel density and that of larvae of other species [COM 98, LEN 08].

\subsubsection{Predation}

Some experiments show that large mobile predators influence the structure of communities on the SEPR by reducing the abundance of limpets through grazing, as well as by eradicating some invertebrate recruits [MIC 02]. Thus, the fish Thermarces cerberus may play a key role by feeding on organisms that control the recruitment of several sessile species [SAN 05]. A camera deployed on the axial segment of the Juan de Fuca ridge revealed that predation by fish and polynoids could be the main source of death in siboglinid tubeworms Ridgeia piscesae [TUN 90a]. Polynoids dominate the guild of predators by feeding not only siboglinids but also on many bacterivore and detritivore species [BER 07]. On the MAR, isotopic signatures and lipid analyses show that the crab Segonzacia mesatlantica and the shrimp Mirocaris fortunata would be predators, feeding on bacterivorous species [COL 02]. More recent studies (isotopic analyses and behavioral study) show that, even though they are at the top of the food chain, both crustacean taxa would be scavengers [DEB 09, MAT 15].

\subsection{Temporal dynamics of hydrothermal ecosystems}

Most temporal studies carried out in the hydrothermal environment are not based on continuous temporal monitoring but on regular, annual or multi-annual visits by manned or unmanned submersibles. Many attempts have been made to deploy deep-sea cameras since the discovery of hydrothermal vents in 1977, but due to the large number of technical failures, very few have succeeded. There are still considerable technological limitations associated with the deployment of cameras for long periods of 
time in this harsh environment. Nevertheless, since about 10-15 years, recent technological developments have facilitated the deployment of deepsea observatories and temporal data are starting to accumulate.

Most temporal studies published to date are restricted to a few known sites and are located on the EPR. There are only few studies on the MAR [COP 07, CUV 11] despite several campaigns in this region. Temporal studies may be divided into two categories: those that began during or following an eruption (section 6.8.1) and those that were monitored over several years at active sites (section 6.8.2). The first are all located in the Pacific Ocean due to the frequency of seismic events and volcanic activity on ridges with high accretion rates. In fact, only one major event has been recorded on the MAR for 40 years [DZI 04] compared with several dozen in the Pacific. Finally, the first articles based on data from deep-sea observatories are currently being published, providing a perspective on the temporal variability of these ecosystems and associated fauna [CUV 14, SAR 14, MAT in press].

\subsubsection{Temporal studies associated with an eruption}

The chronology is as follows: the initial faunal communities are buried under basaltic lava and, several years later, the sites are recolonized by new communities. New emission sites are first covered by extensive white microbial mats that cover fresh lava flows [TSU 01]. The surrounding water may be milky-colored due to the presence of microorganism flocculates. Then, mobile species are observed, feeding on this new biological production [DES 98, MAR 09]. Several months later, the microbial cover decreases and hydrothermal emissions concentrate in more restricted zones.

The recovery of a community after a disturbance varies according to the pool of species and depends on the larvae available in the region as well as the size of the zone affected [KIM 96]. In the hydrothermal ecosystem, the recolonization of a new site can be rapid, from several days to several weeks, if the conditions are favorable. However, it takes several years before all species from the initial community recolonize a site. Disturbances caused by an eruption appear to directly affect the "pool" of available larvae and consequently, the structure of new colonizing communities [MUL 10]. 


\subsubsection{Sites at GSC and EPR}

Discovered in 1977 on the Galapagos ridge, the Rose Garden site is the first site to be discovered [LON 77]. In the 1980s, many studies were carried out and in 2002, this site was revisited. The initial flourishing hydrothermal communities were buried under fresh basaltic larva [SHA 98] and a new diffuse emission site, with low temperatures, was discovered approximately $300 \mathrm{~m}$ to the northwest. This site was called "Rosebud" and is characterized by the presence of assemblages of small siboglinids $(<6 \mathrm{~cm})$, Bathymodiolin mussels, anemones and vesicomyid bivalves colonizing fissures in the fresh basaltic seafloor.

In April 1991, a series of underwater volcanic eruptions led to the formation of several hydrothermal sites between $9^{\circ} 45^{\prime}$ and $9^{\circ} 52^{\prime} \mathrm{N}$ on the EPR. A large proportion of the ridge summit was covered, wiping out almost all faunal communities present [DES 98]. The sites were buried under fresh lava and new sites, devoid of megafauna, were created. A microbial cover attracted large populations of crabs Bythograea thermydron and other mobile species. Nine months later, this microbial cover was greatly reduced and fissures were occupied by dense populations of the tubeworm Tevnia jerichonana. After 2.5 years, large colonies of Riftia pachyptila were present in all preexisting colonies of Tevnia. After 3.5 years, small mytilids Bathymodiolus thermophilus were observed close to these assemblages and approximately 1 year later, they were attached to siboglinid tubes [SHA 98]. More than 4 years later, Bathymodiolus thermophilus surrounded most living siboglinid assemblages, even replacing some of them. In fact, due to their ability to divert fluids, Bathymodiolin mussels caused a significant decrease in the $\mathrm{H}_{2} \mathrm{~S}$ available [LUT 08]. In this sequence, Tevnia jerichonana would be the pioneer species, gradually replaced by Riftia pachyptila, which would then be excluded by B. thermophilus. Another large eruption occurred in January 2006, destroying an entire hydrothermal site at $9.5^{\circ} \mathrm{N}$. While most of the hydrothermal systems were dominated by Bathymodiolin mussels before the eruption, Tevnia jerichonana rapidly colonized the new emission sites, characterized by an increase in temperature and sulfide concentrations [LUT 08].

\subsubsection{NEPR sites}

The colonization of new hydrothermal sites was monitored for 2 years following an eruption on the CoAxial segment in 1993 [TUN 97]. The eruption was caused by an intrusion of lava [DZI 07] and characterized by a high abundance of microorganisms from subsurface [JUN 95]. This 
microbial population seems to have played an important role in the recruitment of macrofauna since sites with high concentrations of microorganisms had a higher density of fauna [TUN 97]. Seven months after the eruption, several species had colonized the active sites. The most abundant species were siboglinids Ridgeia piscesae, alvinellids Paralvinella pandorae as well as nemerteans. Within 2 years, a third of the regional pool of species was present at the site. This colonization was linked to an increase in temperature and concentrations of $\mathrm{H}_{2} \mathrm{~S}$. However, after 2 years, some sites were already in decline. The succession of species at these senescent sites differs from that observed at active sites, since alvinellids disappeared and many predators (crabs and octopus) were observed.

In 1986, a hot water plume rose $800 \mathrm{~m}$ above the sea floor and a second mega plume was observed in 1987, indicating a volcanic eruption on the North Cleft segment. The faunal succession patterns were observed between 1988 and 1994 [TSU 01]. In 1988, 2 years after the eruption, large areas of microbial mats, thick clusters of Ridgeia piscesae, high densities of Paralvinella pandorae and the presence of fissures in the basalt, emitting "microbial flocs", were observed. More than half of the species in the segment were present. From 1988 to 1990, the microbial coverage and extent of colonization by $P$. pandorae decreased, siboglinids increased and the "floc" disappeared. Five years after the eruption, most low temperature sites were gone and, by 1994, they had all disappeared. High temperature emissions, however, remained. The similarity of the fauna between 1988 and 1994 did not appear to be linked to the region, nor to the year but instead to local habitat characteristics (sulfide input, food availability and competition) which would represent key factors structuring these communities.

In 1998, intense earthquakes were detected on the Axial Volcano and a new lava flow, covering the faunal communities in place, was found a few months later. New active sites, where temperatures reached $80^{\circ} \mathrm{C}$, were sampled for 4 years after the eruption [MAR 09]. Just after the eruption, the layer of basalt, covered with microbial mats, attracted alvinellids and polynoids. In June 1999, siboglinids and other species began to colonize the site [LEV 02]. Contrary to what had been observed on the CoAxial segment, polychaetes took more than 3 years to colonize all the new active sites despite the presence of a source population [MAR 09]. Paralvinella pandorae dominated all siboglinid assemblages in the first year. During the second year, limpets (Lepetodrilus fucensis) increased in abundance, exceeding the densities of $P$. pandorae in the third year. Two and half years after the eruption, all new active sites were 
colonized by siboglinids and over $64 \%$ of known species of this volcano were present. The causes of this "delay" in siboglinid colonization are unknown, but the $\mathrm{H}_{2} \mathrm{~S} /$ heat ratio was higher at the sites before the worms arrived.

\subsubsection{Temporal studies of active sites}

Hydrothermal vents are extremely dynamic, despite the absence of catastrophic events such as volcanic eruptions. The distribution of emission zones at the same site may vary. The geological structures themselves are constantly changing, some grow, others are eroded and the substratum itself is getting modified over time. Finally, the physico-chemical characteristics of the habitats colonized by fauna are also changing, causing variations in the structure of communities.

\subsubsection{GSC and EPR sites}

After its first visit in 1979, the GSC was revisited in 1985. During this period, major changes to the fauna were observed, despite the presence of stable emissions [HES 88]. In 1979, siboglinid polychaete worms Riftia pachyptila were abundant and dominated almost all active sites, while in 1985 their abundance was reduced to $10 \%$, being replaced by mytilid mussels Bathymodiolus thermophilus, which then dominated. The abundance of squat lobsters Munidopsis subsquamosa had greatly increased. Even the density of the whelk Phymorhynchus sp., which lives on the periphery and at senescent sites, increased. In 1985, the population of clams Calyptogena magnifica increased, and by 1988, it was surrounded by assemblages of mussels, likely due to a decrease in emissions. In fact, clams can insert their feet into cracks to obtain sulfides. A decrease in filter-feeding organisms was also observed. Between 1985 and 1990, the community barely changed, despite an increase in the abundance of fauna at the periphery of the active sites [DES 98].

Between 1984 and 1987, changes in subsurface circulation on the hydrothermal field at $13^{\circ} \mathrm{N}$ resulted in the cessation of the activity of two active sites and the reactivation of a previously non-active area [DES 98]. In 1984, the temperature of the Genesis edifice was that of seawater and only one assemblage of small Bathymodiolin mussels and a few empty tubes of Tevnia jerichonana were present. In 1987, the Genesis site appeared to have reactivated and warm fluids $\left(<23^{\circ} \mathrm{C}\right)$ as well as microbial mats were visible close to emission zones. The fauna was dominated by the crab Bythograea 
thermydron well as large populations of Tevnia jerichonana, together with small Riftia pachyptila [DES 98]. Three years later, populations of Tevnia were replaced by small Riftia. Active edifices greater than $5 \mathrm{~m}$ in height were created and colonized by large populations of alvinellids dominated by A. pompejana. In 1991 and 1992, hydrothermal emissions seem to have stabilized and the communities described remained unchanged. Four years later, several edifices had collapsed, illustrating the short lifetime ( $\sim 5$ years) of the active sites in this field.

One site, called "Clam Acres" located at $21^{\circ} \mathrm{N}$, was visited in 1979, 1982 and 1990 [DES 98]. Large clusters of Riftia were found close to hydrothermal emissions, their tubes densely colonized by limpets. The summit of the edifices was covered by mineralized tubes of Alvinella pompejana. Bathymodiolus were absent [HES 88]. Peripheral areas were sparsely covered by dead vesicomyid shells. The emissions and distribution of communities appeared to remain constant between 1979 and 1990, indicating a decadal stability.

\subsubsection{NEPR sites}

Hydrothermal species of the Axial volcano were distributed along a horizontal gradient from the center to the periphery [MAR 02]. The zonation changes as the distance to the emission sites increases. Along this gradient Ridgeia piscesae, Paralvinella pandorae and P. palmiformis were found near sources and tended to disappear toward peripheral areas, while gastropods (Lepetodrilus fucensis and Depressigyra globulus) occurred in the same proportions along this gradient. In 1986, a video camera was deployed on the "mushroom" site on this volcano. The most remarkable phenomenon was the rapid collapse of small anhydrite chimneys which resulted in the death of $44 \%$ Ridgeia piscesae worms within the first 26 days of the study [TUN 90b], confirming the significant potential impact of these natural disturbances on the structure of hydrothermal communities.

Six assemblages of fauna were identified on S\&M, a large hydrothermal edifice on the Main Endeavour Field. Assemblages were distributed heterogeneously in relation with changes in environmental conditions [SAR 97, SAR 99a]. Four assemblages include Ridgeiapiscesae and two others are dominated byalvinellids (Paralvinella sulfincola and P. palmiformis). Community dynamics was monitored between 1991 and 1995 during repeated visits. The percentage of coverage by different assemblages varied over time and 
several bare areas were colonized. Assemblages of $P$. palmiformis, Lepetodrilus fucensis and gastropods (Provanna variabilis and Depressigyra globulus) as well as assemblages of senescent siboglinids increased, indicating a decrease in fluid input. The assemblages identified may reflect various stages of succession initiated by variations in fluid flow and porosity. The progressive mineralization of edifices causes changes in flow on small spatial scales and the succession occurs at the same time as the substratum evolves [SAR 02]. Gradually, as the mineralization and succession of the edifice progress, biotic factors such as predation and competition play an increasing significant role.

\subsubsection{MAR sites}

The hydrothermal vent TAG, located at a depth of 3,600 m, was the first hydrothermal vent field discovered on this ridge. The hydrothermal community here has been long known and a temporal study of this fauna was conducted between 1994 and 2004 [COP 07]. This study showed that there were no significant differences in coverage and abundance of the shrimp Rimicaris exoculata, one of the dominant assemblage of this site. This stability coincides with that of the geochemistry of high temperature fluids on the same time scale.

The hydrothermal vent field Lucky Strike $(1,700 \mathrm{~m})$ is undoubtedly the most studied on the MAR. With an area of $1 \mathrm{~km}^{2}$, it is one of the largest known active vent field and is home to over 20 active edifices [OND 09]. It has been visited during many cruises and the images collected by different submersibles between 1994 and 2008 were analyzed [CUV 11]. Four assemblages of fauna, associated with the vent mussel Bathymodiolus azoricus and shrimp Mirocaris fortunata and two types of substrata were identified on the Eiffel Tower edifice [CUV 09b]. The temporal dynamics was assessed on the edifice, between its different sides and also on a small scale, which was a first for a MAR edifice. The percentage of colonization and mussel coverage remained stable throughout the 14-year study. However, on a shorter time scale and smaller spatial scale, significant differences in microbial coverage and distribution of fauna were observed. These fluctuations were linked to changes in the local hydrothermal activity and a negative correlation between the percentage of colonization of the edifice and the number of active emissions on the structure (black smoker, flanges and diffusion zones) was detected. The orientation of the edifice with regard to the hydrodynamic process was suggested to play an important role in the distribution of fauna [CUV 11]. 


\subsubsection{Deep-sea observatories}

Deep-sea observatories, autonomous (uncabled) or wired with fiber optic cables, have experienced a recent boom. These observatories are used to continuously monitor the ecosystems studied using several sensors. In total, two deep-sea observatories are currently in operation on hydrothermal sites. The EMSO-Azores observatory, located on the Lucky Strike field on the MAR, has been in operation since 2010. It has two autonomous nodes of energy that provide to the various sensors control and energy [COL 11]. These nodes communicate acoustically with a surface buoy, which sends the data via satellite to the archive center at the Ifremer center in Brest (France, Figure 6.7). The Ocean Network Canada observatory is located on the Juan de Fuca tectonic plate in the northeast of the Pacific Ocean. It is traversed by an $800 \mathrm{~km}$ long fiber optic cable that supplies six energy nodes. One of the nodes is deployed at the Endeavour segment hydrothermal vents at the base of the Grotto active edifice $(2,200 \mathrm{~m})$. In operation since 2009, this network allows $24 \mathrm{~h}$ access to data via the Internet and enables the remote control of instruments. Data are archived in Port Alberoni, located on the Vancouver Island (British Columbia, Canada).

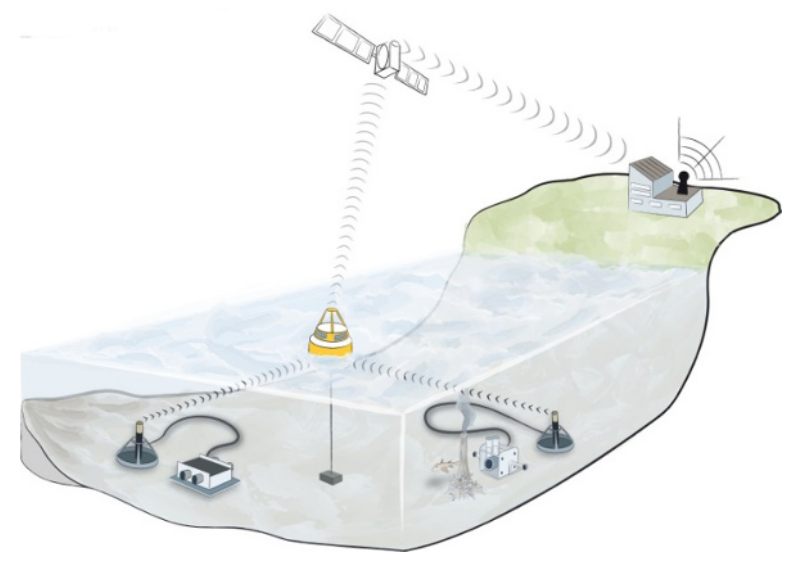

Figure 6.7. The EMSO-Azores observatory has been in operation since 2010 on the Lucky Strike vent field $(1,700 \mathrm{~m})$ on the Mid-Atlantic Ridge. It was implemented by French interdisciplinary teams - Institut de Physique du Globe, University of Toulouse and Ifremer (Capsule Graphik 2014)

The first ecological studies from these two observatories show the relative annual stability of vent communities, both on the MAR [SAR 14] 
and the Juan de Fuca Ridge [CUV 14]. Few environmental variations were recorded during the periods studied so far (48 days on the MAR and 28 days on NEPR). Temperature fluctuations were closely linked to those of the tides, with a potential impact on the behavior and physiology of the surrounding fauna. A correlation between the activity of siboglinids coming in and out their tubes and the tidal cycle supports this hypothesis [CUV 14]. The EMSO-Azores observatory was also used to analyze the behavior of two species of crustaceans, the shrimp Mirocaris fortunata and the crab Segonzacia mesatlantica [MAT 15] in relation with abiotic factors. Further studies are currently underway, in particular attempting to associate variations in faunal abundance with larger scale phenomena such as currents, vent fluid temperature and earthquake intensity.

\subsubsection{Dispersion of larvae and recruitment}

Invertebrates that colonize vent sites maintain their populations due to the dispersion of larvae that must travel long distances to find a substratum and settle successfully. The geographical isolation of breeding groups and the genetic pool explain the inverse relationship observed between the distance of the sites and the similarity of fauna. Thus, the nearest hydrothermal fields, located on adjacent ridge segments, share pools of genes and species [SHA 98], whereas remote sites share few species [TUN 88].

Most hydrothermal species are sedentary and produce planktonic larvae that are dispersed by the currents [ADA 12]. Larval dispersion maintains populations and ensures genetic connectivity between sites. The larvae can colonize new habitats or even an existing community, influencing the structure and diversity. Understanding dispersion between active sites is essential to understand community dynamics and identify the processes that help maintain the diversity of hydrothermal ecosystems.

Larvae of hydrothermal species have morphological and physiological characteristics that differ from those of adults. They survive in the water column until they arrive at an optimal habitat. Studying the larvae in deepsea ecosystems is still a challenge, mainly because of the difficulty in sampling. It is not known where these larvae end up once released since larval densities, even near active sites, are extremely low [MUL 05]. Several indicators suggest that the larvae could be found higher in the water column. For example, some experiments have shown that the 
larvae of several hydrothermal species such as those of Riftia pachyptila and Alvinella pompejana could not tolerate the higher temperature conditions found in the habitats of adults [PRA 07].

The dispersion process is closely linked to the reproduction of hydrothermal species. While reproductive mechanisms are relatively well known for most of the dominant species, there is little information about their lifecycles due to sampling constraints. Indeed, these sites are revisited by research vessels at the same time of the year, which does not allow access to the intra-annual variability in reproduction. Only a few studies have directly observed spawning events. Otherwise, they are often deduced from observations of species breeding cycles (gonadal maturation, presence of spawning females or juveniles, etc.). Reproduction is continuous in several hydrothermal species [TYL 03], which would explain the rapid colonization of new active sites. However, for others such as Bathymodiolus azoricus on the Menez Gwen field (MAR) and the crab Bythograea thermydron on the SEPR, reproduction may be influenced by surface production [TEN 06] and therefore be discontinuous. The French campaign BICOSE, conducted in early 2014, revealed the presence of a high percentage of spawning females of the shrimp Rimicaris exoculata and large populations of juveniles, absent from previous campaigns, indicating the possible temporality in the reproduction of this species. Other factors, such as tides, seem to influence reproduction in some alvinellids.

It is still difficult to estimate the development time of larval hydrothermal species, particularly due to difficulties in raising them in pressurized containers. However, some experiments have been carried out in required conditions to observe larval development at their natural pressure. But, none of them has yet made it possible to observe the whole developmental sequence [PRA 01]. The lifetime of larvae in the water column will depend on their ability to feed themselves. Non-planktotrophic larvae have a shorter planktonic stage and disperse over shorter distances than those that feed. However, the special conditions of deep-sea environments could favor a longer residence time [TYL 03] and some species, such as Alvinella pompejana, have the ability to halt their development until they encounter a favorable habitat [PRA 01].

The coupling between the temporal monitoring, larval culture and the study of currents have led to an increased understanding of larval dispersal of hydrothermal species. Identification and modeling hydrodynamic 
processes are key elements to explain these dispersal mechanisms [ADA 12]. Thus, currents, directly related to seabed topography, will influence the trajectory and the distance traveled by benthic species larvae before their recruitment. Larval behavior, meanwhile, is beginning to be studied in some species, providing basic knowledge about their dispersal capacities. Other additional approaches such as colonization experiments provide an insight into the larval installation process, the species pool available over time and the role of environmental conditions in this colonization [CUV 14, MUL 98]. Recent technological developments such as seafloor observatories and sequential larvae pumps allow intra-annual temporal variations to be observed and therefore collect basic data on the lifecycle of hydrothermal species.

\subsection{Mineral resources and exploitation}

The global demand for minerals is increasing and the risk of shortages of strategic metals, are evident, particularly in Europe [FOU 12]. It is in this context that several countries are currently seeking alternatives, which include the exploitation of deep-sea mineral resources. The resources of the deep sea could become vital to meet the global demand for energy and raw materials. Like oil, mineral resources are non-renewable and their formation is slower than their rate of consumption [FOU 12].

Scientific research over the last 40 years in the deep-sea has helped highlight several geological and geochemical processes that promote the concentration of metals in certain types of ecosystems (nodules, crusts and hydrothermal sulfides) and the creation of energy resources (oil, methane clathrate and hydrogen). These resources include hydrothermal minerals, rich in several base metals (copper, zinc, lead, silver, gold, etc.) as well as rare metals (indium, germanium, cadmium, selenium, etc.). These strategic metals are those whose demand is the greatest [FOU 12].

Hydrothermal activity contributes to the concentration of metals that accumulate in the form of massive deposits of several hundred meters in diameter. A large proportion of copper, zinc, silver and gold exploited ashore are also extracted from these types of deposits. Sulfide edifices may account for several millions to several tens of million tons of ore. While current technologies can easily localize new active hydrothermal sites, no systematic method is recognized to search for inactive sites, for exploitation. 
So far, only operations carried out near the seabed can locate them and drilling is essential to accurately characterize the content of these deposits and assess their economic potential. Current knowledge estimates that approximately 100 hydrothermal vents could be exploitable. Technological developments to explore deep-sea environments and associated ecosystems are required in order to assess the resources and the potential impacts of such an operation on their associated communities.

To date, there are 26 applications to explore deep-sea resources in the "Zone ${ }^{14 "}$. While in exclusive economic zones ${ }^{15}$, where sovereign states regulate access to marine mineral resources (exploration and exploitation of the continental shelf), beyond the continental shelf, in international waters, this mandate falls under the International Seabed Authority ${ }^{16}$ (ISA). The most active countries in the exploration of these resources are China, Korea, Russia, India and France. France currently has two exploration permits: one for nodules in the Clarion-Clipperton zone (granted in 2001), located in the center of the Pacific Ocean and more recently a permit for polymetallic sulfides on the MAR (signed in 2014).

The exploitation of resources contained in hydrothermal deposits is imminent. Thus, Nautilus Minerals Inc. is the first company in the world to have a license to explore polymetallic sulfide deposits on the seabed of the EEZ of Papua New Guinea (Solwara I site). Having fulfilled all obligations associated with this license, Nautilus proceeded to the second phase and received its first license to exploit these resources. Despite the fact that many technical details are still unknown, extraction scenarios are similar (see Figure 6.8). A device is used to extract the ore base by scraping and grinding the surface; the ore is raised to the surface by pumping, with discharge of part of the waste into the water column in the form of fine particles. The ore is then accumulated on barges plying up a terrestrial deposit. The operating time of a deposit is estimated to be short, between 2 and 5 years.

Our knowledge of the fauna colonizing inactive hydrothermal deposits is scarce. However, the complexity of the topography and the presence of hydrodynamic conditions and heterogeneous substrata suggest an increased

14 The international seabed (called the "Zone") is composed of the seabeds and their subsoil beyond the limits of the national court.

15 EEZ: exclusive economic zone.

16 ISA: International Seabed Authority. 
biodiversity [FOU 12]. While it is difficult to assess with certainty what the consequences of such an activity may be on marine communities, several studies suggest a range of potential impacts, including both direct and indirect impacts. The first direct impact is the complete destruction of the habitat in the mined areas, decimating the entire associated fauna. The spread of sediment plumes, the physico-chemical changes in the environment, noise and light are some of the indirect factors that may affect benthic and surrounding pelagic communities. A recent study compared the potential impact of the exploitation of resources to those that occur naturally during an underwater volcanic eruption [VAN 14]. However, our current knowledge is still insufficient to establish reasonable plans for the protection of the environment and biodiversity associated with deep-sea ecosystems. Acquiring basic knowledge is essential to better understand their functioning, biodiversity, natural variability and resilience. This knowledge is essential for the development of management tools that will assess the potential impacts of such an operation and, if applicable, to ensure the total or partial restoration of these original ecosystems following an operation. Establishing protected areas, to ensure the conservation of biodiversity at the regional level, is essential [FOU 12]. However, only mobilization will allow scientists to make decisions with the knowledge necessary for the establishment of these areas, for the sustainability and respect of the environment.

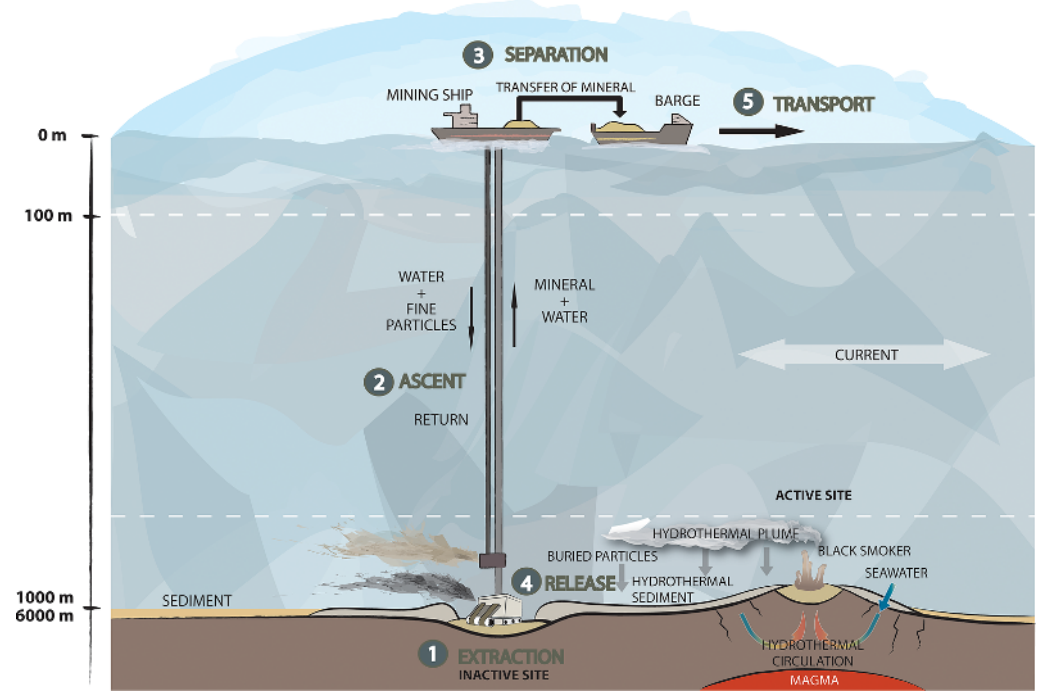

Figure 6.8. Diagram showing the potential exploitation of sulfide deposits from the deep sea (Capsule Graphik 2014) 

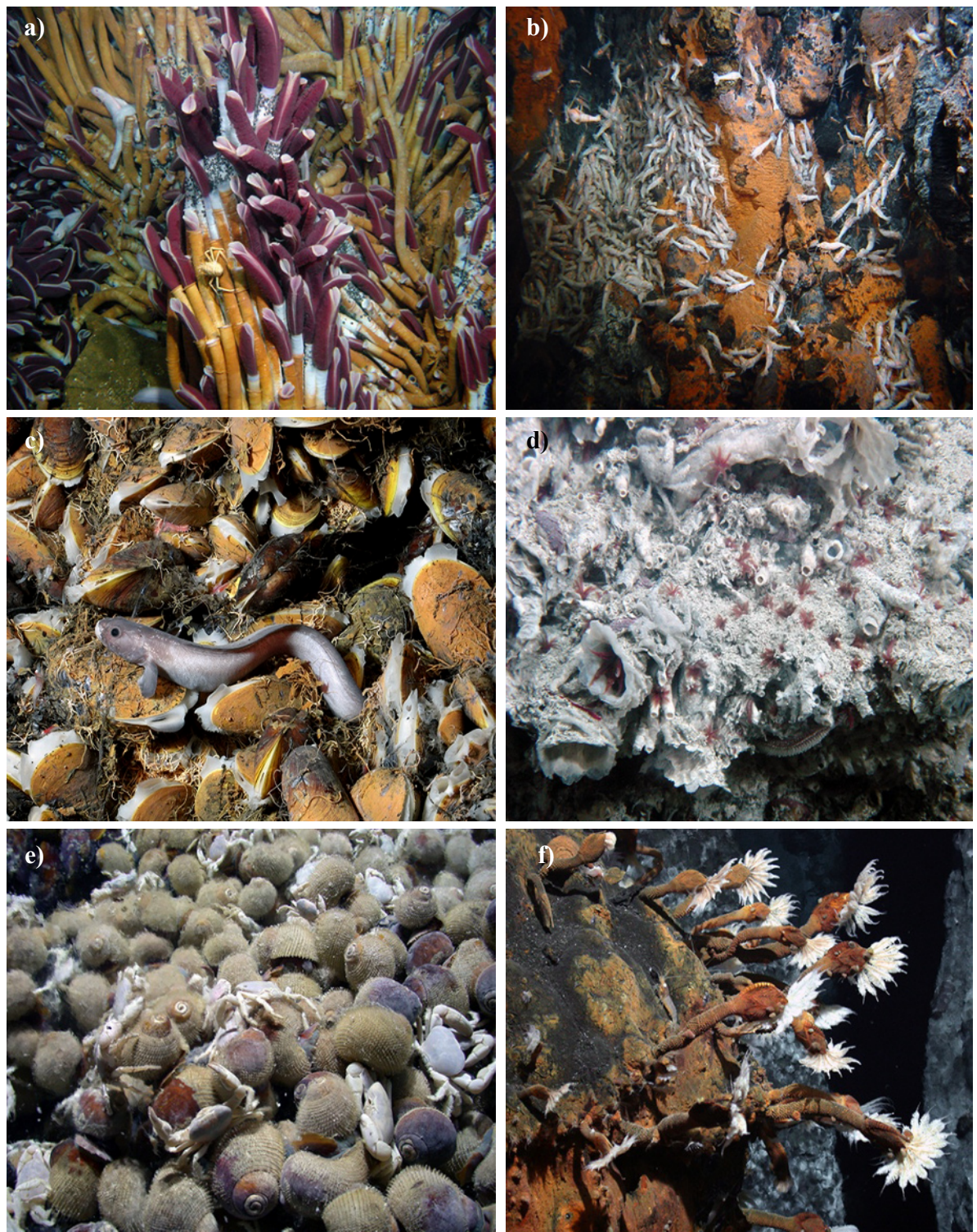

Figure 6.9. The main engineer species of the hydrothermal ecosystem. a) Riftia pachyptila, EPR; b) Alvinella pompejana, EPR; c) Bathymodiolus azoricus, MAR; d) Rimicaris exoculata, MAR; e) Alviniconcha spp., Lau basin; f) Vulcanolepas sp., Lau basin. (Photos a, b, $c$ and d belong to Ifremer and photos eandfarea courtesy of C. Fisher, Penn State University). For a color version of the figure, see color section 


\subsection{Bibliography}

[ADA 12] Adams D.K., Arellano S.M., Govenar B., "Larval dispersal: vent life in the water column", Oceanography, vol. 25, pp. 256-268, 2012.

[ARN 98] ARndt C., SchiedeK D., Felbeck H., "Metabolic responses of the hydrothermal vent tube worm Riftia pachyptila to severe hypoxia", Marine Ecology Progress Series, vol. 174, pp. 151-158, 1998.

[ARP 84] ARP A.J., ChILDRESS J.J., FISHER C.R., "Metabolic and blood-gas transport characteristics of the hydrothermal vent bivalve Calyptogena magnifica", Physiological Zoology, vol. 57, pp. 648-662, 1984.

[AUZ 88] AuZende J.M., Yves L., Marseet B., "Recent geodynamic evolution of the North Fiji Basin, Southwest Pacific", Geology, vol. 16, pp. 925-929, 1988.

[BAT 05] BAtes A.E., TUNNICLIfFE V., LEE R.W., "Role of thermal conditions in habitat selection by hydrothermal vent gastropods", Marine Ecology Progress Series, vol. 305, pp. 1-15, 2005.

[BAT 10] BAtesA.E., LeE R.W., TunNiClifFe V. et al., "Deep-sea hydrothermal vent animals seek cool fluids in a highly variable thermal environment", Nature Communications, vol. 1, pp. 12, 2010.

[BER 07] BERGQUIST D.C., ECKNER J.T., URCUYO I.A. et al., "Using stable isotopes and quantitative community characteristics to determine a local hydrothermal vent food web”, Marine Ecology Progress Series, vol. 330, pp. 49-65, 2007.

[BOE 00] Boetius A., Ravenschlag K., Schubert C.J. et al., "A marine microbial consortium apparently mediating anaerobic oxidation of methane", Nature, vol. 407, pp. 623-626, 2000.

[BOR 02] Borowski C.G.O., Krieger J., AmAnN R. et al., "New aspects of the symbiosis in the provannid snail Ifremeria nautilei from the North Fiji Back Arc Basin”, Cahiers de Biologie Marine, vol. 43, pp. 321-324, 2002.

[CHA 00] Charlou J.L.D.J., Douville E., Jean-Baptiste P. et al., "Compared geochemical signatures and the evolution of Menez Gwen $\left(37^{\circ} 50^{\prime} \mathrm{N}\right)$ and Lucky Strike $\left(37^{\circ} 17^{\prime} \mathrm{N}\right)$ hydrothermal fluids, South of the Azores triple junction on the Mid-Atlantic Ridge", Chemical Geology, vol. 171, pp. 49-75, 2000.

[CHA 04] Chausson F., SANGLiER S., LeIze E. et al., "Respiratory adaptations of a deep-sea hydrothermal vent crab", Micron, vol. 35, pp. 27-29, 2004.

[CHA 09] Charmasson S., SARradin P.-M., LE FAOUdER A. et al., "High levels of natural radioactivity in biota from deep-sea hydrothermal vents: a preliminary communication", Journal of Environmental Radioactivity, vol. 100, pp. 522526, 2009. 
[CHE 91] Chevaldonne P., Desbruyeres D., Lehaitre M., "Time-series of temperature from three deep-sea hydrothermal vent sites", Deep-Sea Research Part I-Oceanographic Research Papers, vol. 38, pp. 1417-1430, 1991.

[CHE 93] Chevaldonne P., Jollivet D., "Videoscopic study of deep-sea hydrothermal vent alvinellid polychaete populations-biomass estimation and behavior”, Marine Ecology Progress Series, vol. 95, pp. 251-262, 1993.

[CHI 91] Childress J.J., Fisher C.R., FAvuZzi J.A. et al., "Sulfide and carbon dioxide uptake by the hydrothermal vent clam Calyptegena magnifica and its chemoautotrophic symbionts", Physiological Zoology, vol. 64, pp. 1444-1470, 1991.

[CHI 92] CHILDRESS J.J., FISHER C.R., "The biology of hydrothermal vent animals-physiology, biochemistry and autotrophic symbioses", Oceanography and Marine Biology, vol. 30, pp. 337-441, 1992.

[COL 02] COlAco A., Dehairs F., DesbruYeres D., "Nutritional relations of deepsea hydrothermal fields at the Mid-Atlantic Ridge: a stable isotope approach", Deep-Sea Research Part I - Oceanographic Research Papers, vol. 49, pp. 395-412, 2002.

[COL 07] Colaco A., Desbruyeres D., Guezennec J., "Polar lipid fatty acids as indicators of trophic associations in a deep-sea vent system community", Marine Ecology - An Evolutionary Perspective, vol. 28, pp. 15-24, 2007.

[COL 11] Colaco A., Blandin J., CAnnat M. et al., "MoMAR-D: a technological challenge to monitor the dynamics of the Lucky Strike vent ecosystem", ICES Journal of Marine Science, vol. 68, pp. 416-424, 2011.

[COM 98] COMTET T., Desbruyeres D., "Population structure and recruitment in mytilid bivalves from the Lucky Strike and Menez Gwen hydrothermal vent fields (37 degrees $17^{\prime} \mathrm{N}$ and 37 degrees 50 'N on the Mid-Atlantic Ridge)", Marine Ecology Progress Series, vol. 163, pp. 165-177, 1998.

[CON 75] CONNELL J.H., "Some mechanisms producing structure in natural communities: a model and evidence from field experiments", Ecology and Evolution of Communities, Belknap Press of Harvard University, MA, 1975.

[CON 12] ConnellyD.P., Copley J.T., Murton B.J. et al., "Hydrothermal vent fields and chemosynthetic biota on the world's deepest seafloor spreading centre", Nature Communications, vol. 3, 2012.

[COP 97] COPLEY J.T.P., TYleR P.A., MURTON B.J. et al., "Spatial and interannual variation in the faunal distribution at Broken Spur vent field (29 degrees N, MidAtlantic Ridge)", Marine Biology, vol. 129, pp. 723-733, 1997. 
[COP 07] COPLEY J.T.P., FlinT H.C., FERRERO T.J. et al., "Diversity of melofauna and free-living nematodes in hydrothermal vent mussel beds on the northern and southern East Pacific Rise", Journal of the Marine Biological Association of the United Kingdom, vol. 87, pp. 1141-1152, 2007.

[COS 08] Cosson R.P., Thiebaut E., COMPAny R. et al., "Spatial variation of metal bioaccumulation in the hydrothermal vent mussel Bathymodiolus azoricus", Marine Environmental Research, vol. 65, pp. 405-415, 2008.

[CUV 09a] Cuvelier D., Sarrazin J., Colaco A. et al., "Distribution and spatial variation of hydrothermal faunal assemblages at Lucky Strike (Mid-Atlantic Ridge) revealed by high-resolution video image analysis", Deep-Sea Research Part I-Oceanographic Research Papers, vol. 56, pp. 2026-2040, 2009.

[CUV 09b] CUVElier D., SARradin P.M., SARRAZIN J. et al., "Hydrothermal faunal assemblages and habitat characterisation at the Eiffel Tower edifice (Lucky Strike, Mid-Atlantic Ridge)", Marine Ecology - An Evolutionary Perspective, vol. 32, pp. 243-255, 2009.

[CUV 11] Cuvelier D., Sarrazin J., Colaco A. et al., "Community dynamics over 14 years at the Eiffel Tower hydrothermal edifice on the Mid-Atlantic Ridge", Limnology and Oceanography, vol. 56, pp. 1624-1640, 2011.

[CUV 14] Cuvelier D., Legendre P., LAes A. et al., "Rhythms and community dynamics of a hydrothermal tubeworm assemblage at main endeavour field - a multidisciplinary deep-sea observatory approach”, Plos One, vol. 9, no. 5, 2014.

[DEB 09] De Busserolles F., SARrazin J., Gauthier O. et al., "Are spatial variations in the diets of hydrothermal fauna linked to local environmental conditions?", Deep-Sea Research Part II - Topical Studies in Oceanography, vol. 56, pp. 1649-1664, 2009.

[DES 94] Desbruyères D., Alayse-Danet A.-M., OHtA S. et al., "Deep-sea hydrothermal communities in Southwestern Pacific back-arc basins (the North Fiji and Lau Basins): composition, microdistribution and food web", Marine Geology, vol. 116, pp. 227-242, 1994.

[DES 98] Desbruyères D., Chevaldonne P., Alayse A.M. et al., "Biology and ecology of the 'Pompeii worm' (Alvinella pompejana Desbruyeres and Laubier), a normal dweller of an extreme deep-sea environment: a synthesis of current knowledge and recent developments", Deep-Sea Research Part II - Topical Studies in Oceanography, vol. 45, pp. 383-422, 1998.

[DES 00] Desbruyères D., Almeida A., Biscoito M. et al., “A review of the distribution of hydrothermal vent communities along the northern Mid-Atlantic Ridge: dispersal vs. environmental controls", Hydrobiologia, vol. 440, pp. 201216, 2000. 
[DES 01] DesbruYÈRES D., BisCoITo M., CAPRAIS J.C. et al., "Variations in deepsea hydrothermal vent communities on the Mid-Atlantic Ridge near the Azores plateau", Deep-Sea Research Part I-Oceanographic Research Papers, vol. 48, pp. 1325-1346, 2001.

[DES 06] Desbruyeres D., Hashimoto J., Fabri M.-C., "Composition and biogeography of hydrothermal vent communities in western pacific back-arc basins", Back-Arc Spreading Systems: Geological, Biological, Chemical, and Physical Interactions, Wiley Ed., 2006.

[DIX 06] Dixon D.R., Lowe D.M., MiLler P.I. et al., "Evidence of seasonal reproduction in the Atlantic vent mussel Bathymodiolus azoricus, and an apparent link with the timing of photosynthetic primary production", Journal of the Marine Biological Association of the United Kingdom, vol. 86, pp. 13631371, 2006.

[DUP 09] DUPERRON S., LORION J., SAMADI S. et al., "Symbioses between deep-sea mussels (Mytilidae: Bathymodiolinae) and chemosynthetic bacteria: diversity, function and evolution", Comptes Rendus Biologies, vol. 332, pp. 298-310, 2009.

[DZI 04] DZIAK R.P., SMITH D.K., BoHNENSTIEHL D.R. et al., "Evidence of a recent magma dike intrusion at the slow spreading Lucky Strike segment, Mid-Atlantic Ridge", Journal of Geophysical Research-Solid Earth, vol. 109, B12102, 2004.

[DZI 07] DZIAK R.P., Bohnenstiehl D.R., Cowen J.P. et al., "Rapid dike emplacement leads to eruptions and hydrothermal plume release during seafloor spreading events", Geology, vol. 35, pp. 579-582, 2007.

[FAB 11] FABRI M.C., BARGAIN A., BRIAND P. et al., "The hydrothermal vent community of a new deep-sea field, Ashadze-1, 12 degrees 58 ' $\mathrm{N}$ on the MidAtlantic Ridge", Journal of the Marine Biological Association of the United Kingdom, vol. 91, pp. 1-13, 2011.

[FEL 85] FELBECK H., " $\mathrm{CO}_{2}$ fixation in the hydrothermal vent tube worm Riftia pachyptial (Jones)", Physiological Zoology, vol. 58, pp. 272-281, 1985.

[FIS 90] Fisher C.R., KenNicutT M.C., BrooKs J.M., "Stable carbon isotopic evidence for carbon limitation in hydrothermal vent vestimentiferans", Science, vol. 247, pp. 1094-1096, 1990.

[FOU 12] FOUQUET Y., LACROIX, D., Les ressources minérales marines profondes, Editions Quae,Versailles, 2012.

[FUS 87] FusteC A., Desbruyeres D., JuniPeR K.S., "Deep-sea hydrothermal communities at $13^{\circ} \mathrm{N}$ on the East Pacific Rise: microdistribution and temporal variations", Biological Oceanography, vol. 4, pp. 121-164, 1987. 
[GAG 91] GAGE J.D., "Biological rates in the deep-sea - a perspective from studies on processes in the benthic boundary layer", Reviews in Aquatic Sciences, vol. 5, pp. 49-100, 1991.

[GIR 06] GIRGUIS P.R., LEE R.W., "Thermal preference and tolerance of alvinellids", Science, vol. 312, pp. 231-231, 2006.

[GOF 04] GofFredi S.K., WAREN A., ORPhAN V.J. et al., "Novel forms of structural integration between microbes and a hydrothermal vent gastropod from the Indian Ocean", Applied and Environmental Microbiology, vol. 70, pp. 30823090, 2004.

[GOL 07] Gollner S., ZeKely J., Govenar B. et al., "Tubeworm-associated permanent meiobenthic communities from two chemically different hydrothermal vent sites on the East Pacific Rise", Marine Ecology Progress Series, vol. 337, pp. 39-49, 2007.

[GOL 10a] Gollner S., IVAnenko V.N., Arbizu P.M. et al., "Advances in taxonomy, ecology, and biogeography of dirivultidae (Copepoda) associated with chemosynthetic environments in the deep sea", Plos One, vol. 5, no. 8, 2010.

[GOL 10b] Gollner S., Riemer B., Martinez Arbizu P. et al., "Diversity of meiofauna from the $9 \hat{\mathrm{A}}^{\circ} 50$ ' $\mathrm{N}$ East Pacific rise across a gradient of hydrothermal fluid emissions", Plos One, vol. 5, no. 8, 2010.

[GOV 05] Govenar B., Le Bris N., Gollner S. et al., "Epifaunal community structure associated with Riftia pachyptila aggregations in chemically different hydrothermal vent habitats", Marine Ecology Progress Series, vol. 305, pp. 67$77,2005$.

[GRA 92] GRASSLE J.F., MACIOLEK N.J., "Deep-sea species richness -regional and local diversity estimates from quantitative bottom samples", American Naturalist, vol. 139, pp. 313-341, 1992.

[GRE 06] Grelon D., Morineaux M., Desrosiers G. et al., "Feeding and territorial behavior of Paralvinella sulfincola, a polychaete worm at deep-sea hydrothermal vents of the Northeast Pacific Ocean", Journal of Experimental Marine Biology and Ecology, vol. 329, pp. 174-186, 2006.

[HAL 08] HALARY S., RiOU V., GAILl F. et al., "3D FISH for the quantification of methane- and sulphur-oxidizing endosymbionts in bacteriocytes of the hydrothermal vent mussel Bathymodiolus azoricus", ISME Journal, vol. 2, pp. 284-292, 2008.

[HAS 01] HASHImOto J., OHTA S., Gamo T. et al., "First hydrothermal vent communities from the Indian Ocean discovered", Zoological Science, vol. 18, pp. 717-721, 2001. 
[HAY 91] HAYMON R.M., FORNARI D.J., EDWARDS M.H. et al., "Hydrothermal vent distribution along the East Pacific Rise Crest $\left(9^{\circ} 09^{\prime}-54^{\prime} \mathrm{N}\right)$ and its relationship to magmatic and tectonic processes on fast-spreading midocean ridges", Earth and Planetary Science Letters, vol. 104, pp. 513-534, 1991.

[HEN 08] Henry M.S., Childress J.J., FigueroA D., "Metabolic rates and thermal tolerances of chemoautotrophic symbioses from Lau Basin hydrothermal vents and their implications for species distributions", Deep-Sea Research Part I Oceanographic Research Papers, vol. 55, pp. 679-695, 2008.

[HES 83] HeSSLER R., SMITHEY W.M., "The distribution and community structure of megafauna at the Galapagos Rift hydrothermal vents", Hydrothermal Processes at Seafloor Spreading Centers, Plenum Press, New York, 1983.

[HES 88] Hessler R., SMithey W.M., Boudrias M.A. et al., "Temporal change in megafauna at the rose garden hydrothermal vent (Galapagos Rift - Eastern Tropical Pacific)", Deep-Sea Research Part I - Oceanographic Research Papers, vol. 35, pp. 1681-1709, 1988.

[HES 91] Hessler R., LonsDAle P.F., "Biogeography of Mariana Trough hydrothermal vent communities", Deep Sea Research Part I - Oceanographic Research Papers, vol. 38, pp. 185-199, 1991.

[HOL 01] Holm N.G., ChaRlou J.L., "Initial indications of abiotic formation of hydrocarbons in the rainbow ultramafic hydrothermal system, Mid-Atlantic Ridge", Earth and Planetary Science Letters, vol. 191, pp. 1-8, 2001.

[HOU 00] Hourdez S., LALlier F.H., De Cian M.C., et al., "Gas transfer system in Alvinella pompejana (Annelida Polychaeta, Terebellida): functional properties of intracellular and extracellular hemoglobins", Physiological and Biochemical Zoology, vol. 73, pp. 365-373, 2000.

[HOU 07] Hourdez S., LALliER F.H., "Adaptations to hypoxia in hydrothermalvent and cold-seep invertebrates", Reviews in Environmental Science and Bio/Technology, vol. 6, pp. 143-159, 2007.

[HUE 11] Huegler M., Petersen J.M., Dubilier N. et al., "Pathways of carbon and energy metabolism of the epibiotic community associated with the deep-sea hydrothermal vent shrimp Rimicaris exoculata", Plos One, vol. 6, no. 1, 2011.

[IVA 11] IVAnenko V.N., Ferrari F.D., DeFaye D. et al., "Description, distribution and microhabitats of a new species of Tisbe (Copepoda: Harpacticoida: Tisbidae) from a deep-sea hydrothermal vent field at the MidAtlantic Ridge (37 degrees N, Lucky Strike)", Cahiers de Biologie Marine, vol. 52, pp. 89-106, 2011. 
[JAN 79] JANNASCH H.W., WIRSEN C.O., "Chemosynthetic primary production at East Pacific sea floor spreading centers", BioScience, vol. 29, pp. 592-598, 1979.

[JAN 95] JANNASCH H.W., Microbial Interactions with Hydrothermal Fluids, American Geophysical Union, Washington, DC, 1995.

[JOH 94] JOHNSON K.S., CHILDRESS J.J., BEEHLER C.L. et al., "Biogeochemistry of hydrothermal vent mussel communities: the deep-sea analogue to the intertidal zone", Deep Sea Research Part I - Oceanographic Research Papers, vol. 41, pp. 993-1011, 1994.

[JUN 95] JUNIPER S.K., MARTINEU P., SARRAzin J. et al., "Microbial-mineral floc associated with nascent hydrothermal activity on Coaxial segment, Juan de Fuca ridge”, Geophysical Research Letters, vol. 22, pp. 179-182, 1995.

[KAR 95] KARL D.M., "Ecology of free-living, hydrothermal vent microbial communities", The Microbiology of Deep-Sea Hydrothermal Vents, CRC Press, New York, pp. 35-124, 1995.

[KeL 07] Kelly N., Metaxas A., Butterfield D., "Spatial and temporal patterns of colonization by deep-sea hydrothermal vent invertebrates on the Juan de Fuca Ridge, NE Pacific", Aquatic Biology, vol. 1, pp. 1-16, 2007.

[KEL 08] Kelly N., MetaXAs A., "Diversity of invertebrate colonists on simple and complex substrates at hydrothermal vents on the Juan de Fuca Ridge", Aquatic Biology, vol. 3, pp. 271-281, 2008.

[KIM 96] KIM J.H., DEWREEDE R.E., "Effects of size and season of disturbance on algal patch recovery in a rocky intertidal community", Marine Ecology Progress Series, vol. 133, pp. 217-228, 1996.

[KIM 98] Kim S.L., MullineauX L.S., "Distribution and near-bottom transport of larvae and other plankton at hydrothermal vents", Deep-Sea Research Part II Topical Studies in Oceanography, vol. 45, pp. 423-440, 1998.

[KOU 07] Kouris A., JuniPer S.K., FrebourG G. et al., "Protozoan-bacterial symbiosis in a deep-sea hydrothermal vent folliculinid ciliate (Folliculinopsis sp.) from the Juan de Fuca Ridge", Marine Ecology - An Evolutionary Perspective, vol. 28, pp. 63-71, 2007.

[LEB 06] Le Bris N., Govenar B., LE GALl C. et al., "Variability of physicochemical conditions in 9 degrees 50'N EPR diffuse flow vent habitats", Marine Chemistry, vol. 98, pp. 167-182, 2006.

[LEL XX] LELIÈVRE Y., Characterization of the factors controlling the dynamics of the macrofauna associated with hydrothermal vents using deep-sea observatory data, $\mathrm{PhD}$ Thesis, University of Montréal, in progress. 
[LEN 08] LeniHan H.S., Mills S.W., MullineauX L.S. et al., "Biotic interactions at hydrothermal vents: recruitment inhibition by the mussel Bathymodiolus thermophilus", Deep-Sea Research Part I - Oceanographic Research Papers, vol. 55, pp. 1707-1717, 2008.

[LEV 02] LeVesque C., JunIPER S.K., "Particulate matter as a food source at a nascent hydrothermal vent on the Juan de Fuca Ridge", Cahiers de Biologie Marine, vol. 43, pp. 289-292, 2002.

[LEV 05] LeVesque C., Limen H., JuniPeR S.K., "Origin, composition and nutritional quality of particulate matter at deep-sea hydrothermal vents on Axial Volcano, NE Pacific", Marine Ecology Progress Series, vol. 289, pp. 43-52, 2005.

[LEV 06] LEVESQUE C., JUNIPER S.K., LIMEN H., "Spatial organization of food webs along habitat gradients at deep-sea hydrothermal vents on Axial Volcano, Northeast Pacific", Deep-Sea Research Part I - Oceanographic Research Papers, vol. 53, pp. 726-739, 2006.

[LIM 07] LIMEN H., LEVESQUE C., JUNIPER S.K., "POM in macro-/meiofaunal food webs associated with three flow regimes at deep-sea hydrothermal vents on Axial Volcano, Juan de Fuca Ridge", Marine Biology, vol. 153, pp. 129-139, 2007.

[LON 77] LONSDALE P., "Deep-tow observations at mounds abyssal hydrothermal field, Galapagos rift", Earth and Planetary Science Letters, vol. 36, pp. 92-110, 1977.

[LUT 01] LUTHER G.W., ROZAN T.F., TAILlEFERT M. et al., "Chemical speciation drives hydrothermal vent ecology”, Nature, vol. 410, pp. 813-816, 2001.

[LUT 08] LUTz R.A., SHANK T.M., LUTHER G.W. et al., "Interrelationships between vent fluid chemistry, temperature, seismic activity, and biological community structure at a mussel-dominated, deep-sea hydrothermal vent along the East Pacific Rise", Journal of Shellfish Research, vol. 27, pp. 177-190, 2008.

[LUT 12] Luther G.W., Gartman A., Yuecel M. et al., "Chemistry, temperature, and faunal distributions at diffuse-flow hydrothermal vents comparison of two geologically distinct ridge systems", Oceanography, vol. 25, pp. 234-245, 2012.

[MAR 97] MARTINEU P., JUNIPER S.K., FiSHER C.R. et al., "Sulfide binding in the body fluids of hydrothermal vent alvinellid polychaetes", Physiological Zoology, vol. 70, pp. 578-588, 1997.

[MAR 02] MARCUS J., TUNNICLIFFE V., "Living on the edges of diffuse vents on the Juan de Fuca Ridge”, Cahiers de Biologie Marine, vol. 43, pp. 263-266, 2002. 
[MAR 09] Marcus J., Tunnicliffe V., ButTerfield D.A., "Post-eruption succession of macrofaunal communities at diffuse flow hydrothermal vents on Axial Volcano, Juan de Fuca Ridge, Northeast Pacific", Deep-Sea Research Part II - Topical Studies in Oceanography, vol. 56, pp. 1586-1598, 2009.

[MAR 12] MARSh L., COPley J.T., Huvenne V.A.I. et al., "Microdistribution of faunal assemblages at deep-sea hydrothermal vents in the Southern Ocean", Plos One, vol. 7, no. 10, 2012.

[MAT 15] Matabos M.C.D., Brouard J., Shillito B. et al., "Behavioural study of two hydrothermal crustacean decapods: Mirocaris fortunata and Segonzacia mesatlantica, from the Lucky Strike vent field (Mid Atlantic Ridge)", Deep Sea Research, Part II, forthcoming 2015 (online 04.2015).

[MiC 02] Micheli F., Peterson C.H., Mullineaux L.S., et al., "Predation structures communities at deep-sea hydrothermal vents", Ecological Monographs, vol. 72, pp. 365-382, 2002.

[MOA 12] Moalic Y., Desbruyeres D., Duarte C.M. et al., "Biogeography revisited with network theory: retracing the history of hydrothermal vent communities", Systematic Biology, vol. 61, pp. 127-137, 2012.

[MUL 95] Mullineaux L.S., WieBe P.H., BAKeR E.T., "Larvae of benthic invertebrates in hydrothermal vent plumes over Juan de Fuca ridge", Marine Biology, vol. 122, pp. 585-596, 1995.

[MUL 98] Mullineaux L.S., Mills S.W., Goldman E., "Recruitment variation during a pilot colonization study of hydrothermal vents $\left(9^{\circ} 50^{\prime} \mathrm{N}\right.$, East Pacific Rise)", Deep-Sea Research Part II - Topical Studies in Oceanography, vol. 45, pp. 441-464, 1998.

[MUl 00] Mullineaux L.S., Fisher C.R., Peterson C.H. et al., "Tubeworm succession at hydrothermal vents: use of biogenic cues to reduce habitat selection error?", Oecologia, vol. 123, pp. 275-284, 2000.

[MUl 05] Mullineaux L.S., Mills S.W., Sweetman A.K. et al., "Vertical, lateral and temporal structure in larval distributions at hydrothermal vents", Marine Ecology Progress Series, vol. 293, pp. 1-16, 2005.

[MUl 09] Mullineaux L.S., Micheli F., Peterson C.H., et al., "Imprint of past environmental regimes on structure and succession of a deep-sea hydrothermal vent community", Oecologia, vol. 161, pp. 387-400, 2009.

[MUL 10] Mullineaux L.S., Adams D.K., Mills S.W. et al., "Larvae from afar colonize deep-sea hydrothermal vents after a catastrophic eruption", Proceedings of the National Academy of Sciences of the United States of America, vol. 107, pp. 7829-7834, 2010. 
[NAK 12] NAKAMURA K., WATANABE H., MiYAZAKi J. et al., "Discovery of new hydrothermal activity and chemosynthetic fauna on the Central Indian Ridge at $18^{\circ}-20^{\circ}$ S”, Plos One, vol. 7, no. 3, 2012.

[NYE 13] NyE V., COPley J.T., TyleR P.A., "Spatial variation in the population structure and reproductive biology of Rimicaris hybisae (Caridea: Alvinocarididae) at hydrothermal vents on the Mid-Cayman spreading centre", Plos One, vol. 8, pp. e60319-e60319, 2013.

[OND 09] OndREAS H., CANNAT M., FouQuet Y. et al., "Recent volcanic events and the distribution of hydrothermal venting at the Lucky Strike hydrothermal field, Mid-Atlantic Ridge”, Geochemistry Geophysics Geosystems, vol. 10, no. 2, 2009.

[POD 09] Podowski E.L., MoORE T.S., ZELnio K.A. et al., "Distribution of diffuse flow megafauna in two sites on the Eastern Lau Spreading Center, Tonga", Deep-Sea Research Part I - Oceanographic Research Papers, vol. 56, pp. 20412056, 2009.

[PON 98] Pond D.W., Bell M.V., DiXON D.R. et al., "Stable-carbon-isotope composition of fatty acids in hydrothermal vent mussels containing methanotrophic and thiotrophic bacterial endosymbionts", Applied and Environmental Microbiology, vol. 64, pp. 370-375, 1998.

[PON 13] Ponsard J., CAmbOn-Bonavita M.-A., ZBinden M. et al., "Inorganic carbon fixation by chemosynthetic ectosymbionts and nutritional transfers to the hydrothermal vent host-shrimp Rimicaris exoculata", ISME Journal, vol. 7, pp. 96-109, 2013.

[POR 15] PORTAIL M., Olu K., EsCOBAR-Briones E., et al., "Comparative study of vent and seep macrofaunal communities in the Guaymas basin", Biogeosciences, forthcoming 2015 .

[PRA 01] Pradillon F., Shillito B., Young C.M. et al., "Deep-seaecology developmental arrest in vent worm embryos", Nature, vol. 413, pp. 698-699, 2001.

[PRA 07] PRAdILlON F., GAILl F., “Adaptation to deep-sea hydrothermal vents: some molecular and developmental aspects", Journal of Marine Science and Technology-Taiwan, vol. 15, pp. 37-53, 2007.

[RAU 79] RAU G.H., HedGeS J.I., " $\mathrm{C}_{13}$ Depletion in a hydrothermal vent mussel suggestion of a chemo-synthetic food source", Science, vol. 203, pp. 648-649, 1979.

[RAV 03] RAVAuX J., GAILl F., LE BRIS N. et al., "Heat-shock response and temperature resistance in the deep-sea vent shrimp Rimicaris exoculata", Journal of Experimental Biology, vol. 206, pp. 2345-2354, 2003. 
[ROG 12] Rogers A.D., Tyler P.A., CONNElly D.P. et al., "The discovery of new deep-sea hydrothermal vent communities in the Southern Ocean and implications for biogeography", Plos Biology, vol. 10, no. 1, 2012.

[ROT 13] Roterman C.N., COPley J.T., Linse K.T. et al., "The biogeography of the yeti crabs (Kiwaidae) with notes on the phylogeny of the Chirostyloidea (Decapoda: Anomura)", Proceedings of the Royal Society B - Biological Sciences, vol. 280, 2013.

[SAN 05] SANChO G., Fisher C.R., Mills S. et al., "Selective predation by the zoarcid fish Thermarces cerberus at hydrothermal vents", Deep-Sea Research Part I-Oceanographic Research Papers, vol. 52, pp. 837-844, 2005.

[SAR 97] SARRAZIN J., ROBIGOU V., JUNIPER S.K. et al., "Biological and geological dynamics over four years on a high-temperature sulfide structure at the Juan de Fuca Ridge hydrothermal observatory", Marine Ecology Progress Series, vol. 153, pp. 5-24, 1997.

[SAR 99a] SARRADIN P.M., CAPRAIS J.C., Riso R. et al., "Chemical environment of the hydrothermal mussel communities in the Lucky Strike and Menez Gwen vent fields, Mid Atlantic ridge", Cahiers de Biologie Marine, vol. 40, pp. 93-104, 1999.

[SAR 99b] SARRAZIN J., JUNIPER S.K., "Biological characteristics of a hydrothermal edifice mosaic community", Marine Ecology Progress Series, vol. 185, pp. 1-19, 1999.

[SAR 99c] SARRAZIN J., JuniPer S.K., MASSOTh G. et al., "Physical and chemical factors influencing species distributions on hydrothermal sulfide edifices of the Juan de Fuca Ridge, northeast Pacific", Marine Ecology Progress Series, vol. 190, pp. 89-112, 1999.

[SAR 02] SARrazin J., Levesque C., Juniper S.K. et al., "Mosaic community dynamics on Juan de Fuca Ridge sulphide edifices: substratum, temperature and implications for trophic structure", Cahiers de Biologie Marine, vol. 43, pp. 275-279, 2002.

[SAR 14] SARRAZIN J., CUVElier D., Peton L. et al., "High-resolution dynamics of a deep-sea hydrothermal mussel assemblage monitored by the EMSO-Acores MoMAR observatory", Deep-Sea Research Part I - Oceanographic Research Papers, vol. 90, pp. 62-75, 2014.

[SAR 15] SARrazin J., Legendre P., DE Busserolles F. et al., "Biodiversity patterns, environmental drivers and indicator species on a high temperature hydrothermal edifice, Mid-Atlantic Ridge", Deep Sea Research, forthcoming 2015 (online 04.2015). 
[SCH 08] Schmidt C., Vuillemin R., Le Gall C. et al., "Geochemical energy sources for microbial primary production in the environment of hydrothermal vent shrimps", Marine Chemistry, vol. 108, pp. 18-31, 2008.

[SHA 98] SHANK T.M., FornARI D.J., VON DAMM K.L. et al., "Temporal and spatial patterns of biological community development at nascent deep-sea hydrothermal vents (9 degrees 50'N, East Pacific Rise)", Deep-Sea Research Part II - Topical Studies in Oceanography, vol. 45, pp. 465-515, 1998.

[SIB 02] SiBuet M., Roy O.-L., Cold Seep Communities on Continental Margins: Structure and Quantitative Distribution Relative to Geological and Fluid Venting Patterns. Ocean Margin Systems, Springer Verlag, Berlin, 2002.

[SIE 99] SiEVERT S.M., Brinkhoff T., MuYZER G. et al., "Spatial heterogeneity of bacterial populations along an environmental gradient at a shallow submarine hydrothermal vent near Milos Island (Greece)", Applied and Environmental Microbiology, vol. 65, pp. 3834-3842, 1999.

[SOM 92] SOMERO G.N., "Adaptations to high hydrostatic pressure”, Annual Review of Physiology, vol. 54, pp. 557-577, 1992.

[STE 88] STEIN J.L., CARY S.C., HeSSLER R.R. et al., "Chemoautotrophic symbiosis in a hydrothermal vent gastropod", Biological Bulletin, vol. 174, pp. 373-378, 1988.

[SWE 13] SWEETMAN A.K., LEVIN L.A., RAPP H.T. et al., "Faunal trophic structure at hydrothermal vents on the southern Mohn's Ridge, Arctic Ocean", Marine Ecology Progress Series, vol. 473, pp. 115-131, 2013.

[TSU 01] TSURUMI M., TUNNICLIFFE V., "Characteristics of a hydrothermal vent assemblage on a volcanically active segment of Juan de Fuca Ridge, northeast Pacific", Canadian Journal of Fisheries and Aquatic Sciences, vol. 58, pp. 530542, 2001.

[TSU 03a] TSuRumi M., DE GraAF R.C., TunNiCliffe V., "Distributional and biological aspects of copepods at hydrothermal vents on the Juan de Fuca Ridge, north-east Pacific ocean", Journal of the Marine Biological Association of the United Kingdom, vol. 83, pp. 469-477, 2003.

[TSU 03b] TSURUMI M., TUNNICLIFFE V., "Tubeworm-associated communities at hydrothermal vents on the Juan de Fuca Ridge, northeast Pacific", Deep-Sea Research Part I - Oceanographic Research Papers, vol. 50, pp. 611-629, 2003.

[TUN 85] TunNicliffe V., JuniPER S.K., De BurGH M., “The hydrothermal vent community on axial seamount, Juan de Fuca Ridge", Bulletin of the Biological Society of Washington, vol. 6, pp. 453-464, 1985. 
[TUN 88] TUNNICLIFFE V., "Biogeography and evolution of hydrothermal vent fauna in the Eastern Pacific Ocean", Proceedings of the Royal Society B Biological Sciences, vol. 233, pp. 347-366, 1988.

[TUN 90a] TUnNiCliffe V., GARrett J.F., Johnson H.P., "Physical and biological factors affecting the behavior and mortality of hydrothermal vent tubeworms (Vestimentiferans)", Deep-Sea Research Part I - Oceanographic Research Papers, vol. 37, pp. 103-125, 1990.

[TUN 90b] TUNNICLIFFE V., JUNIPER S.K., "Dynamic character of the hydrothermal vent habitat and the nature of sulfide chimney fauna", Progress in Oceanography, vol. 24, pp. 1-13, 1990.

[TUN 96] TUNNICLIFFE V., FOWLER C.M.R., "Influence of sea-floor spreading on the global hydrothermal vent fauna", Nature, vol. 379, pp. 531-533, 1996.

[TUN 97] TunNicliffe V., EmBley R.W., Holden J.F., et al., "Biological colonization of new hydrothermal vents following an eruption on Juan de Fuca Ridge", Deep-Sea Research Part I - Oceanographic Research Papers, vol. 44, pp. 1627-1644, 1997.

[TYL 99] TYLER P.A., YOUnG C.M., "Reproduction and dispersal at vents and cold seeps", Journal of the Marine Biological Association of the United Kingdom, vol. 79, pp. 193-208, 1999.

[TYL 03] TYLER P.A., YOUNG C.M., "Dispersal at hydrothermal vents: a summary of recent progress", Hydrobiologia, vol. 503, pp. 9-19, 2003.

[URC 03] Urcuyo I.A., Massoth G.J., Julian D. et al., "Habitat, growth and physiological ecology of a basaltic community of Ridgeia piscesae from the Juan de Fuca Ridge", Deep-Sea Research Part I - Oceanographic Research Papers, vol. 50, pp. 763-780, 2003.

[VAN 89] VAN DOVER C., FRY B., "Stable isotopic compositions of hydrothermal vent organisms", Marine Biology, vol. 102, pp. 257-263, 1989.

[VAN 94] VAN DOVER C., FRY B., "Microorganisms as food resources at deep-sea hydrothermal vents", Limnology and Oceanography, vol. 39, pp. 51-57, 1994.

[VAN 00] VAn Dover C., The Ecology of Deep-Sea Hydrothermal Vents, Princeton University Press, Princeton, 2000.

[VAN 02] Van Dover C., German C.R., Speer K.G. et al., "Marine biology evolution and biogeography of deep-sea vent and seep invertebrates", Science, vol. 295, pp. 1253-1257, 2002.

[VAN 14] VAN DOVER C., "Impacts of anthropogenic disturbances at deep-sea hydrothermal vent ecosystems: a review", Marine Environmental Research, vol. 102, pp. 59-72, 2014. 
[VIS 91] VISMANN B., "Sulfide tolerance - physiological mechanisms and ecological implications", Ophelia, vol. 34, pp. 1-27, 1991.

[WAR 03] WAREN A., BengtSON S., GofFredi S.K. et al., "A hot-vent gastropod with iron sulfide dermal sclerites", Science, vol. 302, pp. 1007, 2003.

[ZAL 98] ZAL F., LeIZE E., LALLIER F.H. et al., "S-sulfohemoglobin and disulfide exchange: the mechanisms of sulfide binding by Riftia pachyptila hemoglobins", Proceedings of the National Academy of Sciences of the United States of America, vol. 95, pp. 8997-9002, 1998.

[ZEK 06] ZeKely J., Van Dover C.L., NemeschKal H.L. et al., "Hydrothermal vent meiobenthos associated with mytilid mussel aggregations from the MidAtlantic Ridge and the East Pacific Rise", Deep-Sea Research Part I Oceanographic Research Papers, vol. 53, pp. 1363-1378, 2006. 